\title{
Reactive extrusion of bio-based polymer blends and composites - Current trends and future developments
}

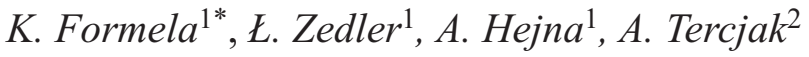 \\ ${ }^{1}$ Department of Polymer Technology, Faculty of Chemistry, Gdansk University of Technology, Gdansk, Poland \\ ${ }^{2}$ Group 'Materials Technologies' (GMT), Department of Chemical and Environmental Engineering, Polytechnic School, \\ University of the Basque Country (UPV/EHU), Plaza Europa 1, 20018 Donostia-San Sebastián, Spain
}

Received 3 July 2017; accepted in revised form 2 September 2017

\begin{abstract}
Reactive extrusion is a cost-effective and environmentally-friendly method to produce new materials with enhanced performance properties. At present, reactive extrusion allows in-situ polymerization, modification/functionalization of polymers or chemical bonding of two (or more) immiscible phases, which can be carried out on commonly used extrusion lines. Although reactive extrusion has been known for many years, its application for processing of bio-based polymer blends and composites is a relatively new direction of scientific research.

This work presents a literature review on recent advances in the processing of bio-based polymer blends and composites via reactive extrusion. We described compatibilization mechanisms for different types of biodegradable polymeric materials based on: (i) aliphatic polyesters, (ii) aliphatic polyesters/starch and (iii) aliphatic polyester/natural rubber systems. A special attention was focused on conventional and dynamic cross-linking of bio-based polymer blends and composites as an effective way to prepare new materials with unique properties e.g. biodegradable thermoplastic elastomers or shape-memory materials. Advantages and limitations affecting future trends in development of biodegradable polymer blends and composites reactive extrusion are also discussed.
\end{abstract}

Keywords: biocomposites, reactive extrusion, compatibilization, bio-based polymer blends

\section{Introduction}

Polymers and polymer-based composites are commonly used in a wide range of industrial applications, which is related to their specific performance properties (e.g. durability, light-weight, corrosion resistance, chemical resistance, etc.), easy processing and relatively low-cost manufacturing. As a consequence, dynamic growth of polymers and polymerbased composites production is observed each year. The global plastics production in 2014 increased to 311 million tonnes with an approximate growth rate of $3.9 \%$ annually [1]. Simultaneously, rapidly increasing amount of waste plastics became a huge environmental, economic and social problem [2-4]. Therefore, searching for new and cost-effective solutions in this field is currently a subject of interest of many academic and industrial research groups around the world.

One of the most common ways to solve the problem of waste plastics is the application of biodegradable and bio-based polymers as pro-ecological alternative for 'conventional' polymers based on petroleum resources. However, at this point it should be mentioned that the final impact of biodegradable and biobased polymers and their composites on the environment is usually variable and depends mainly on polymer matrix, fillers or other additives (e.g. cross-linking agents, plasticizers, foaming agents, stabilizers, etc.) used during their preparation. Therefore, these environmental-friendly materials can be classified in 
three ways. First classification is based on the origin of polymer matrix, as natural and synthetic polymers [5]. Second classification is related to biodegradability of the used polymer or polymer blends, which can be fully, partially or non-biodegradable [6]. The last classification depends on the content of renewable components in polymer blends or composites, which can be prepared from petroleum-based, partially or fully bio-based components [7].

As presented in Table 1, estimated data show that in 2016 the global production of biodegradable polymers exceeded 760 thousand tonnes, while the production of non-biodegradable polymers from natural resources is around 1300 thousand tonnes. Furthermore, the prediction is that in 2019 the global production capacity of biodegradable polymers will continuously increase to almost 1290 thousand tonnes and for non-biodegradable polymers based on natural resources the level of production will increase above 6500 thousand tonnes. This indicates that during the next two years the total global production capacity of biodegradable and non-biodegradable polymers from natural resources will increase almost four times [8], which confirms the dynamic development of this polymeric materials group.

Manufacturing of polymer blends and composites via melt-compounding is a commonly applied method to fabricate new materials with desirable properties $[9,10]$. Main advantages of this method are elimination of complicated processes (e.g. polymerization reactions, etc.) and application of commercially available components. A wide range of possible selections of polymeric material compositions and their processing conditions can be a useful tool for easy tailoring of their respective properties [11-13]. Furthermore, melt-compounding is usually performed in extruders commonly used in the industry. Extrusion is one of the fastest developing method of polymer processing [14], which is due to continuity and short time of the

Table 1. Global production capacities of biodegradable polymers and non-biodegradable polymers from natural resources [8]

\begin{tabular}{|c|c|c|c|}
\hline Year & $\begin{array}{c}\text { Biodegradable } \\
\text { polymers } \\
{\left[\mathbf{M g} \cdot \mathbf{1 0}^{\mathbf{3}}\right]}\end{array}$ & $\begin{array}{c}\text { Non-biodegradable } \\
\text { polymers from } \\
\text { natural resources } \\
{\left[\mathbf{M g} \cdot \mathbf{1 0}^{\mathbf{3}}\right]}\end{array}$ & $\begin{array}{c}\text { Total capacity } \\
{\left[\mathbf{M g} \cdot \mathbf{1 0}^{\mathbf{3}}\right]}\end{array}$ \\
\hline 2016 & 762 & 1291 & 2053 \\
\hline 2017 & 901 & 2511 & 3412 \\
\hline 2018 & 1287 & 5511 & 6798 \\
\hline 2019 & 1287 & 6561 & 7848 \\
\hline
\end{tabular}

process, high mixing efficiency, high capacity, good quality of obtained products, diversity and versatility of this technology. As a result of above mentioned factors, research focusing on biodegradable polymer blends and composites obtained via melt-compounding enjoys growing interest among many academic and industrial research groups $[15,16]$. However, physical blending defined as simple mixing in the melt state without any chemical reactions between components, usually results in weak interfacial adhesion between phases, which leads to unsatisfactory physico-mechanical properties of obtained polymeric materials and strongly limits their further applications. Therefore, most of the bio-based polymer blends and composites require further compatibilization $[17,18]$, resulting in the enhancement of their performance properties. In this field the in-situ processing via reactive extrusion seems to be one of the most efficient methods to improve interface interactions between used components. However, application of reactive extrusion during processing of biodegradable polymer blends or composites is a relatively new field of research. According to the best of our knowledge, first comprehensive review about reactive extrusion of biodegradable polymers was presented in 2006 by research group of Prof. Dubois from University of Mons (Belgium) [19] and then successfully updated in next years [20,21].

Reactive extrusion involves carrying out a designed chemical reaction between the used components to modify the properties of existing polymeric materials or for producing new ones in a highly efficient and flexible way. Therefore, this technique can be successfully applied during in-situ polymerization of biodegradable polymers [22, 23], modification/functionalization of natural fibers/fillers [24] or modification/ compatibilization of biodegradable or bio-based polymer blends and composites [25], which confirms the versatility of this processing method.

This work presents a literature review on reactive extrusion and compatibilization mechanisms of various bio-based polymer blends, such as poly(lactic acid)/ poly(e-caprolactone) (PLA/PCL), poly(lactic acid)/ thermoplastic starch (PLA/TPS), poly(E-caprolactone)/natural rubber (PCL/NR), poly(lactic acid)/natural rubber (PLA/NR), etc. Furthermore, recent advances in reactive extrusion during modification/ functionalization of natural fillers/fibers and compatibilization of biocomposites are presented and discussed. We hope that this comprehensive review work 
will provide new, useful information for students and researchers starting studies in this field.

\section{Extruders as chemical reactors - basic concepts}

An extruder can be considered to be a horizontal chemical reactor equipped with one, two, three or more internal screws for constant conveying of reactants in the variable form, such as a solid, melt, liquid or gas. The comparison between a single-, twinand triple-screw extruder is presented in Table 2.

Single- and twin-screw extruders are commonly used in the industry for the processing of polymers, food, pharmaceutics and other materials with complex compositions or different viscosities. Comparing to single-screw extruders, twin-screw extruders offer higher melting, mixing and devolatilization capability, which is a main reason for their more frequent use during reactive extrusion. Twin screw extruders are classified depending on the direction of screw rotation (a co-rotating or a counter-rotating) and the distance between the screws (intermeshing or non-intermeshing). The most commonly used types in the industry are co-rotating intermeshing twin screw extruders, which work at much higher screw speed and generate higher shear forces than counter-rotating twin screw extruders. Currently, counter-rotating twin screw extruders are widely used for polymers with low thermal stability during processing (mainly poly (vinyl chloride) and its copolymers). It seems that counter-rotating twin screw extruders could find application for processing of selected biopolymers and biodegradable polymers characterized by low resistance to thermo-mechanical degradation. However, up to now information published in this field are very limited [26, 27].
Co-rotating twin screw extruders are usually installed in a segmented barrel, each segment of which can be independently heated or cooled externally. Additionally, internal heat is generated during shearing and mixing of viscous polymeric material in extruder. The sources of internal and external heat provide energy necessary for activation of chemical reactions. Segmented construction of barrel allows better control of the temperature inside the extruder. This is very important, especially in case of reactive processing, where some problems with heat removal from material during exothermic reactions may occur.

Furthermore, modular design of screws in co-rotating extruders allows easy modification of screw design. Application of variable screws elements (e.g. conveying, kneading, dispersive mixing, etc.) combined with external heating, allows determination of the total energy and mixing efficiency of the material in each barrel section. This affects the flexibility and versatility of co-rotating twin screw extruders as industrial chemical reactors. The appearance of laboratory scale a co-rotating twin screw extruder and selected geometry of screw elements are presented in the Figures 1 and 2.

Interesting alternative to conventional single- and twin-screw extrusion is triple-screw extrusion, which is relatively new technology. According to the literature, first triangle-arrayed triple-screw extruder was designed by a research group from Beijing University of Chemical Technology and was patented in 2001 [28], while first trials in industrial scale were performed in 2006 [29, 30]. This new equipment for polymer processing, provides advantages in compounding of polymeric blends and composites. Superior blending and dispersing performance of triple-screw extruder is due to flow and mixing characteristics which

Table 2. Comparison between single-, twin- and triple-screw extruder

\begin{tabular}{|l|c|c|c|c|}
\hline \multirow{2}{*}{ Item } & \multirow{2}{*}{ Single-screw extruder } & \multicolumn{2}{c|}{ Twin-screw extruder } & \multirow{2}{*}{ Triple-screw extruder } \\
\cline { 3 - 4 } & & counter-rotating & co-rotating & \\
\hline Screw design & non-modular & non-modular & modular & modular \\
\hline Feeding & fair & good & good & good \\
\hline Melting & good & good & very good & excellent \\
\hline Distributive mixing & good & fair & very good & excellent \\
\hline Dispersive mixing & good & very good & very good & excellent \\
\hline Heat generation capability & very good & good & very good & very good \\
\hline Pressure generation capability & good & very good & good & good \\
\hline Wiping & poor & good & very good & very good \\
\hline Degassing & fair & good & good & good \\
\hline
\end{tabular}

${ }^{*}$ in conical twin screw extruders 


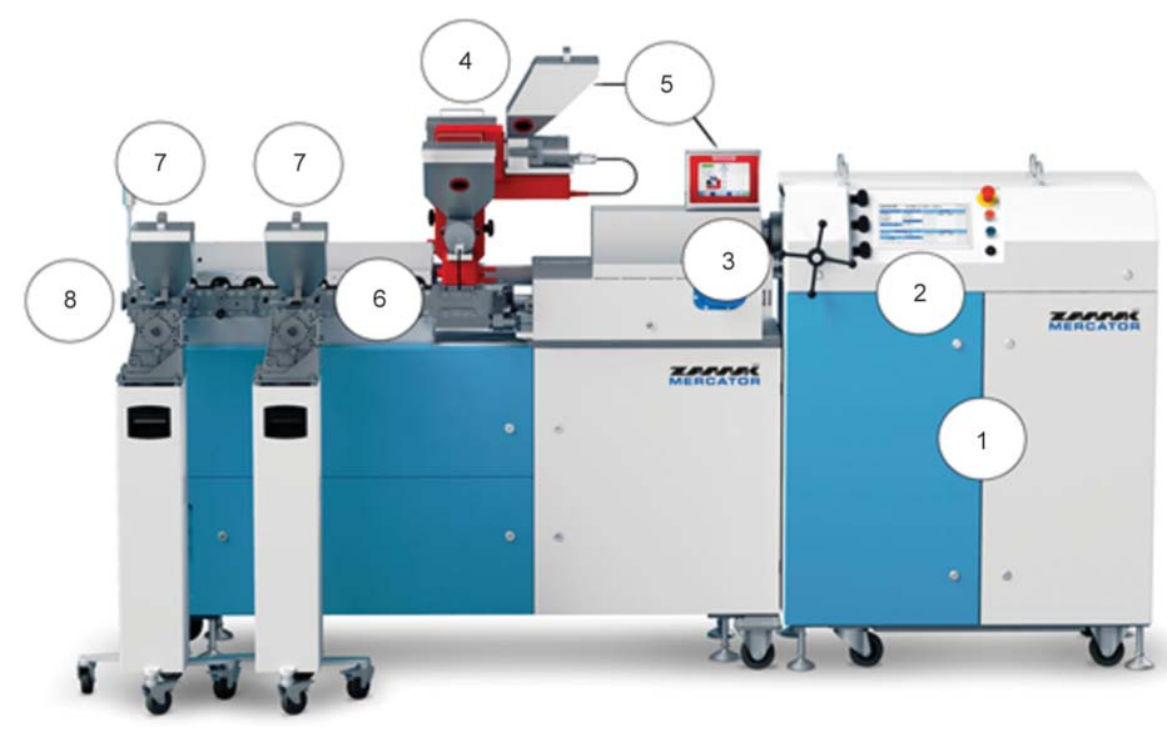

Figure 1. Laboratory a co-rotating twin-screw extruder series REM model 2x24, where: 1 - motor unit, 2 - PLC control panel of extruder, 3 - gearbox, 4 - hopper, 5 - gravimetric feeders with PLC control panel, 6 - extrusion barrel, 7 - side feeders, 8 - extrusion die (reprinted with permission from Zamak Mercator Sp. z o.o., Skawina, Poland, http://www.zamakmercator.pl/)

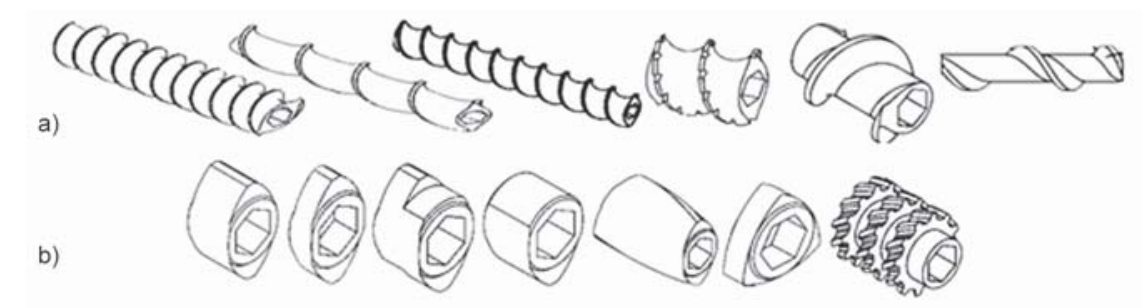

Figure 2. Selected screw elements geometry: a) examples of conveying and degassing elements; b) examples of mixing and dispersing elements (reprinted with permission from Zamak Mercator Sp. z o.o., Skawina, Poland, http://www.zamakmercator.pl/)

are different from traditional single and twin-screw extruders. Construction solutions applied in triplescrew extruders increased residence time of polymer inside the barrel and outperforms shear flow acting on processed materials [31]. Furthermore, triplescrew extruders have higher efficiency of plasticization and mixing than co-rotating intermeshing twinscrew extruders [32]. Therefore, triple-screw extruders are suitable for processing of high viscosity polymers or polymers with higher content of fillers [33]. Additionally, published data indicate that in triplescrew extruders the power consumption is 1.5 times higher than in co-rotating twin-screw extruders, while simultaneously their productivity increase around 1.3 times [34].

However, despite of above mentioned advantages of triple screw extrusion the research works about its application in polymer technology are still very limited [35-37], while its using during reactive processing is practically unknown. This is due to its high costs related to complicated screw geometry and barrel construction, comparing to single- or twin-screw extruders. Nevertheless, recently triple screw extruders were successfully applied for preparation of biobased materials, such as microcellular poly(lactic acid)/talc biocomposites [38], poly(lactic acid)/poly (vinyl alcohol) blends [39] or poly(lactic acid)/poly (ethylene glycol) porous scaffolds [40-42]. In our opinion, application of triple-screw extrusion during reactive extrusion of 'conventional' and biodegradable polymers will be developing in near future.

It is well known that final properties of polymer materials (including biodegradable polymer blends and composites) obtained through extrusion are depending on chemical structure of used components and their physico-chemical properties. The used components must be in a physical form suitable for stable, thermomechanical processing. Otherwise, elevated temperature and high shear forces during processing might cause partial degradation of the used components resulting in the emission of volatile organic compounds [43-45]. This usually results in instability of the 
extrusion process, related to pressure fluctuation inside extruder barrel or significant increase of pressure in extrusion die, what can be a serious threat for extruder operator.

Other crucial factors affecting extrusion efficiency are extrusion conditions, such as barrel temperature, screw speed, shear forces, residence time distribution, etc. These conditions have significant impact on the homogeneity of obtained materials and consequently on their processing and performance properties. The parameters affecting the final properties of bio-based polymer blends and composites obtained via reactive extrusion are summarized in the Figure 3. As presented above, using extruders (especially a corotating twin screw and triple-screw extruders) allows tailoring the energy and mixing conditions of the material in each barrel section, which affects the efficiency of mass and heat transfer. Furthermore, comparing to 'conventional' chemical reactors the application of extruders allows processing of viscous polymers and highly filled polymers. Other important advantage of the extruders as reactors is the absence or reduced content of solvent as reaction medium, which eliminates additional technological operations, such as recovery of solvent or purification of the final product. These are the main factors affecting continuous development of reactive extrusion during laboratory and industrial synthesis and processing of various polymers, polymer blends and composites (including biodegradable ones). As presented in Figure 4, this research trend corresponds with the number of items published in 2010-2015 and their further citations.

\section{Reactive extrusion as a green route for filler/fiber modification}

Natural fiber composites (NFCs) and wood polymer composites (WPCs) can be defined as biocomposites consisting of one or more cellulosic filler/fiber and one or a mixture of polymers. Cellulose rich by-products, generated by wood and agricultural industry, can be used as reinforcements or modifiers of polymeric matrix [46]. This reduces material costs and provides specific properties of biocomposites, such as low density, high stiffness, corrosion resistance, low hazard, renewable nature and biodegradability [47-49]. These advantages caused that NFCs and WPCs are more often used as building and automobile products and as environmental friendly alternative for pure polymers [50-52]. The performance properties of NFCs and WPCs depend on physical and chemical interactions between non-polar polymer matrix and hydrophilic cellulosic filler/fiber. Significant difference in chemical structure and polarity of

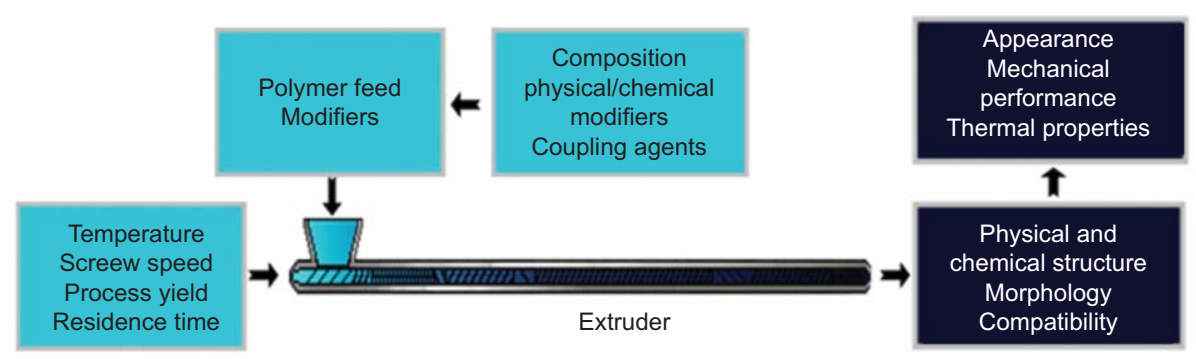

Figure 3. Parameters affecting the final properties of bio-based polymer blends and composites obtained via reactive extrusion
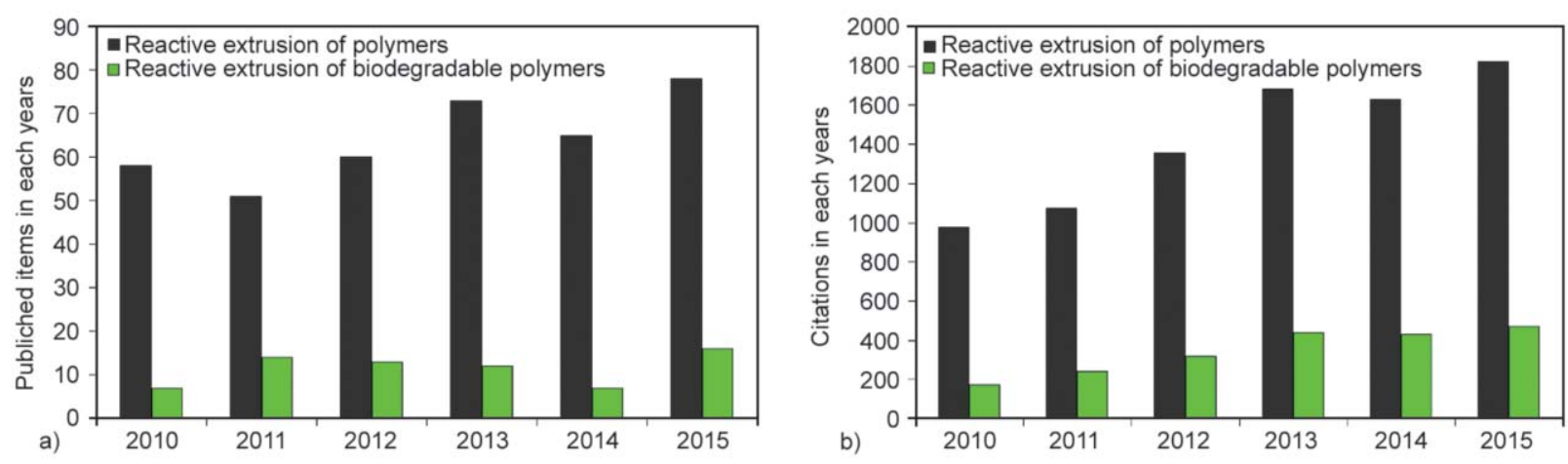

Figure 4. Research works about reactive extrusion of polymers published (a) and cited b) in the period 2010-2015 (presented results according to $\mathrm{WoS}^{\mathrm{TM}}$ data base) 
used components usually results in their weak interfacial adhesion. Therefore, numerous routes to improve interactions between the matrix and filler (or fiber) and enhance the reinforcing effect of the filler (or fiber) have been developed [53, 54]. Among them two main strategies can be observed. First of them is related to the modification of the polymer matrix $[55,56]$, while second is focused on size reduction [57], treatment or functionalization of cellulosic filler/fiber. In this subchapter we will focus on the second route related to the surface of filler/fiber, which can be successfully modified by silane treatment $[58,59]$, mercerization $[60,61]$, acetylation [62, 63] maleic anhydride treatment [64], esterification and etherification [65, 66], isocyanate [67], potassium permanganate [68] and other chemical treatment methods [69-71]. Furthermore, different kinds of surfactants and plasticizers applied as physical additives were considered as wetting agents to reduce the tensions in boundary between polymer matrix and reinforcement phase [72-74]. However, surface treatment of natural fillers/fibers using above mentioned methods is usually performed periodically in the presence of high amount of solvent, which results in high final costs of the modified fillers/fibers and limits their further applications.
Therefore, reactive extrusion is considered as fast, solvent-free and low-cost and pro-ecologic alternative for 'conventional' modification methods of natural fibers or fillers. Carlborn and Matuana [75] used reactive extrusion for modification of wood particles with maleated polyolefins. As presented in Figure 5, chemical reaction of maleated polyolefins and wood particles takes place between the maleate groups of the polyolefin and hydroxyl groups present on the wood surface. The effects of extrusion conditions (temperature and screw speed), molecular weight and content of maleated polyolefins on the efficiency of the wood particles modification were evaluated. It was observed that level of grafting of maleated polyolefin onto wood particles is determined by the maleated polyolefin content, while its molecular weight has small impact on the grafting efficiency. Surprisingly, no significant difference was noticed in the grafting efficiency under variable extrusion conditions. This could be explained by small length of plasticizing unit in the extruder used (screw diameter of $32 \mathrm{~mm}$ and an length to diameter ratio $L / d$ ratio of 13 ), which leads to short residence time distribution of processed material inside barrel. Furthermore, the same authors demonstrated that wood particles modified with maleated polyolefins (without any additional binder)

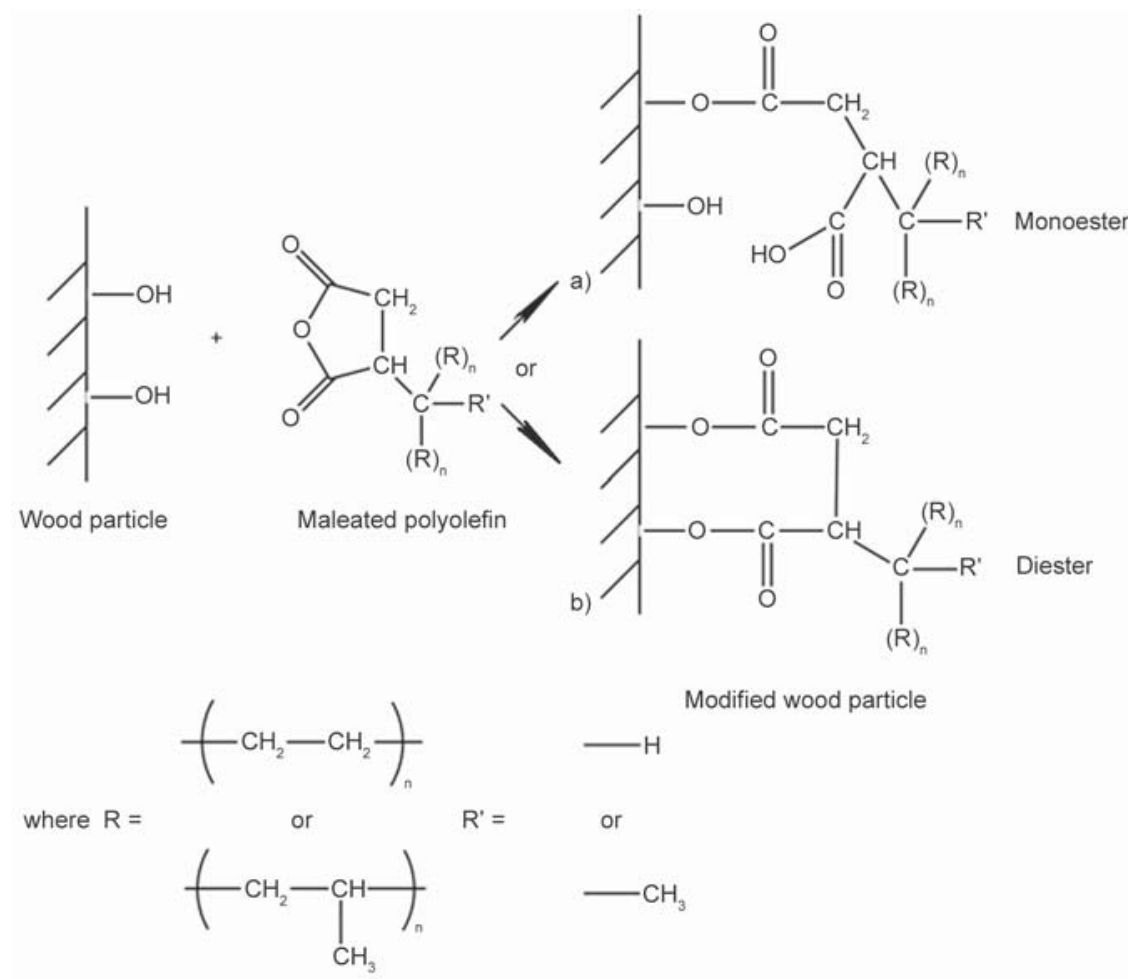

Figure 5. Mechanism of chemical reaction between wood particles and maleated polyolefins. Scheme based on [75]. 
can be successfully applied as materials for manufacturing of composite panels, while their mechanical properties were similar (or even better) comparing to conventional particleboard present on the market [76].

Wei et al. [77] proposed grafting of poly(3-hydroxybutyrate) (PHB) onto cellulose fiber via in-situ reactive extrusion. The reaction between PHB and cellulose fiber was performed at $175^{\circ} \mathrm{C}$, while dicumyl peroxide (DCP) was used as radical initiator. The scheme of reactions between used components is presented in Figure 6. The authors studied the efficiency of cellulose-g-PHB copolymer formulation as a function of reaction time (from 5 to 15 minutes) and DCP concentration (in the range: $2-5 \mathrm{wt} \%$ ). The highest yield of cellulose- $g$-PHB copolymer was obtained after reaction performed in 5 minutes with $2 \mathrm{wt} \%$ of DCP. The results show that new bonds formed during grafting enhanced the thermal stability of PHB and reduced its degree of crystallinity, which suggested that also the brittleness of PHB was decreased. Furthermore, the final properties of cellulose- $g$-PHB can be tailored by different ratio of used component (wt $\%$ PHB and wt $\%$ cellulose) or varying reaction conditions. This approach broadens the processing window for cellulose reinforced biocomposites, which can be used such as packaging, building materials or automotive parts.

Bhandari et al. [78] studied the effects of $\mathrm{NaOH}$ content, water to ethanol ratio and their interactions on the physico-chemical properties and morphology of carboxymethyl cellulose prepared from cotton linter pulp sheets via reactive extrusion. Obtained results revealed a strong correlation between the effects of $\mathrm{NaOH}$ and water concentration on the degree of substitution and crystallinity, which affected the liquid uptake properties of carboxymethyl cellulose. The degree of substitution values decreased with increasing content of $\mathrm{NaOH}$ and increased with increasing amount of ethanol in water/ethanol mixtures, while generally the degree of crystallinity determined for modified cellulose showed opposite trend. The final properties of obtained products were compared with commercially available carboxymethyl cellulose with tradename Aquasorb ${ }^{\mathrm{TM}}$ A500. It was noticed that the rate of liquid uptake for carboxymethyl cellulose prepared without ethanol was significantly improved and much higher than that of commercial Aquasorb $^{\mathrm{TM}}$ A500. This confirms that carboxymethyl cellulose prepared via reactive extrusion could be successfully used as a super absorbent.

Zhang et al. [79] used a co-rotating twin screw extruder during in-situ modification of cellulose with ionic liquid as reaction medium and with urea, phthalic anhydride (PA), maleic anhydride (MA) and butyl glycidyl ether (BGE) as modifiers. The results indicate that modification effectiveness decrease in the sequence $\mathrm{MA}>\mathrm{PA}>\mathrm{BGE}>$ urea. This is due to smaller molecular weight and less steric hindrance of MA, which affects its reactivity and favored the grafting of MA into the surface of cellulose. Comparing to cellulose with other modifiers, cellulose$g$-MA had a lower crystallinity and higher thermal stability. Furthermore, spinning solution of cellulose-g-MA showed lower viscosity and exhibited better spinnability.

Vandenbossche and coworkers [80-83] presented an interesting method of lignocellulosic biomass modification based on reactive extrusion combined with bio-catalytic enzymatic hydrolysis. As presented in Figure 7, this method proceeds in three stages: an alkaline pretreatment, a neutralization stage and finally

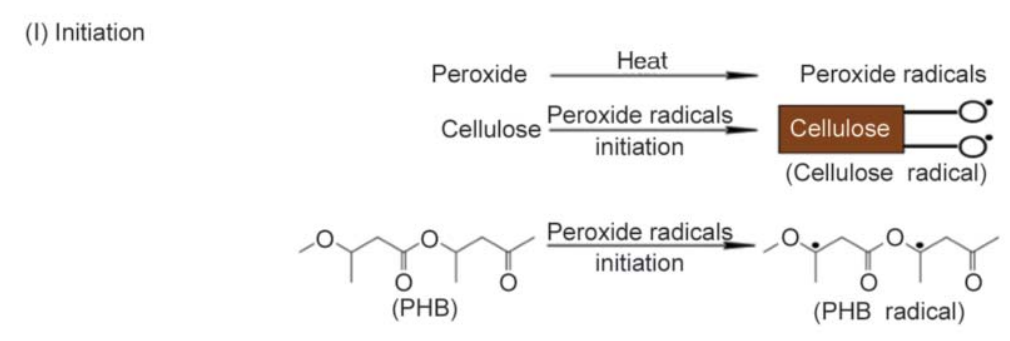

(II) Termination

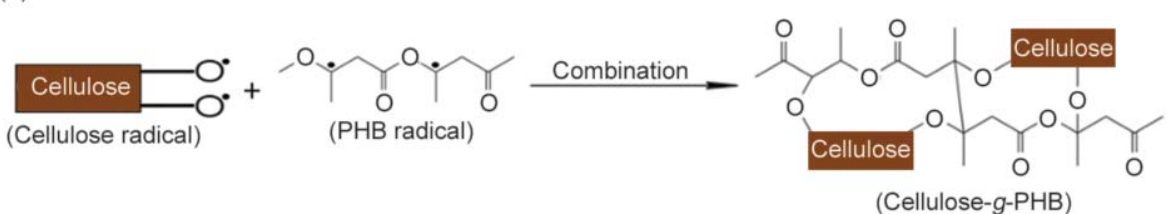

Figure 6. The scheme of grafting the PHB onto cellulose fibers via in-situ reactive extrusion. Scheme based on [77]. 


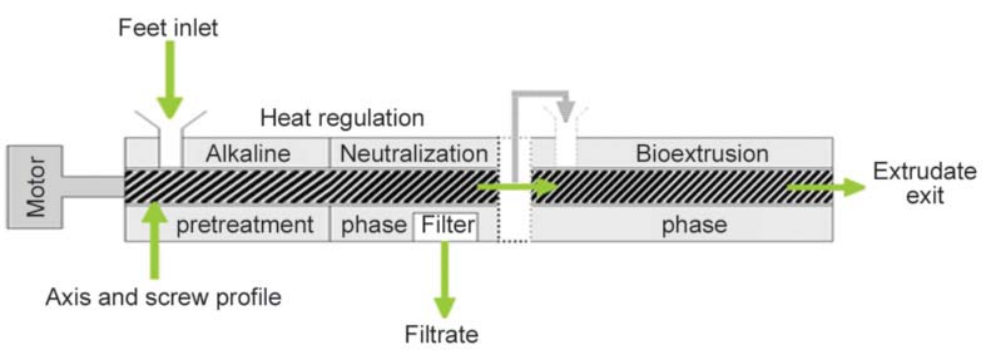

Figure 7. Scheme of lignocellulosic biomass modification via reactive extrusion combined with bio-catalytic enzymatic hydrolysis. Scheme based on [80].

enzyme impregnation stage, during which hemicelluloses and cellulose saccharification occurs. Although twin screw extrusion pretreatment was adopted mostly for production of bioethanol from agro-industrial by-products rich in cellulose $[84,85]$, we believe that in near future reactive extrusion combined with enzymatic treatment could be use to enhance interactions between natural fillers/fibers and polymer matrix. Vaidya et al. [86] studied the effects of extrusion temperature, catalyst content, acid anhydride type (maleic anhydride, succinic anhydride, dodecenyl succinic anhydride) and different weight ratios of wood waste (and cellulose, hemi-cellulose isolated from thereof), to succinic anhydride on the esterification reaction efficiency. The reactivity of individual anhydride was: (i) succinic anhydride - cellulose $>$ wood waste $>$ hemi-cellulose; (ii) maleic anhydride - wood waste $>$ hemi-cellulose $>$ cellulose and (iii) dodecenyl succinic anhydride - wood waste $\approx$ cellulose $>$ hemi-cellulose. The effect of catalyst was highly variable and depended on the type of biomass, cyclic anhydride and temperature. It was observed that the highest acid value was obtained for succinylation of cellulose which is two times higher compared to succinylation of waste wood or hemicellulose. Under optimum conditions $\left(T=190^{\circ} \mathrm{C}\right.$, waste wood/succinic anhydride ratio $1 / 0.43(\mathrm{w} / \mathrm{w}))$, mixtures of monoand di-esters are formed.

Recently, Cardoso et al. [87] modified the oat hull fibers with alkaline hydrogen peroxide via reactive extrusion. The obtained functionalized oat hull fibers were further compounded with a poly(butylene adipate-co-terephthalate)/thermoplastic starch blend. The results revealed that rougher surfaces observed in the treated fibers improved their interfacial adhesion with the polymeric matrix. On the other hand, this surprisingly did not improve the mechanical properties or thermal stability of examined biocomposites. The lack of reinforcement effect was also observed by Yang et al. [88], who used bleached extruder chemo-mechanical pulp fiber as reinforcement of poly(lactic acid) matrix. This phenomenon is probably due to the intense chemical process associated with high shear forces acting on fibers during shearing reactive extrusion, which partially destroy the fiber structure and affect its size and aspect ratio.

\section{Biodegradable polymer blends}

Melt-compounding of biodegradable polymer blends based on commercial aliphatic polyesters such as poly (lactic acid) (PLA), poly ( $\varepsilon$-polycaprolactone) (PCL), poly(3-hydroxybutyrate) (PHB), poly(butylene-adipate-co-terephtalate) (PBAT), poly(butylene succinate) (PBS), and also thermoplastic starch (TPS) or natural rubber (NR), gained much attention from researchers, which is related to their relatively easy processing, suitable usage properties and good quality/ price ratio of the final products. In this subchapter, we described compatibilization mechanisms for different bio-based blends obtained via reactive extrusion.

\subsection{Aliphatic polyesters blends}

Harada et al. [89] used lysine triisocyanate (LTI); lysine diisocyanate (LDI); 1,3,5-tris(6-isocyanatohexyl)-1,3,5-triazinane-2,4,6-trione (Duranate TPA100); 1,3,5-tris(6-isocyanatohexyl)biuret (Duranate 24A-100) and an industrial epoxide-trimethylolpropane triglycidyl ether (Epiclon 725) as reactive compatibilizers of PLA/PCL blends. The impact strength results indicate that compatibility of PLA/ PCL blend (in ratio 80/20) decrease in the sequence LTI $>$ LDI $>$ Duranate TPA-100 $>$ Duranate 24A$100>$ Epiclon 725. Furthermore, PLA/PCL blend compatiblized with LTI surpassed the impact strength of general-purpose poly(acrylonitrile-butadienestyrene) copolymer. This indicates that in studied conditions the isocyanates improved the impact strength of PLA/PCL blends, while the epoxides did not. The scheme of reaction between PLA, PCL and isocyanates is presented in the Figure 8. 


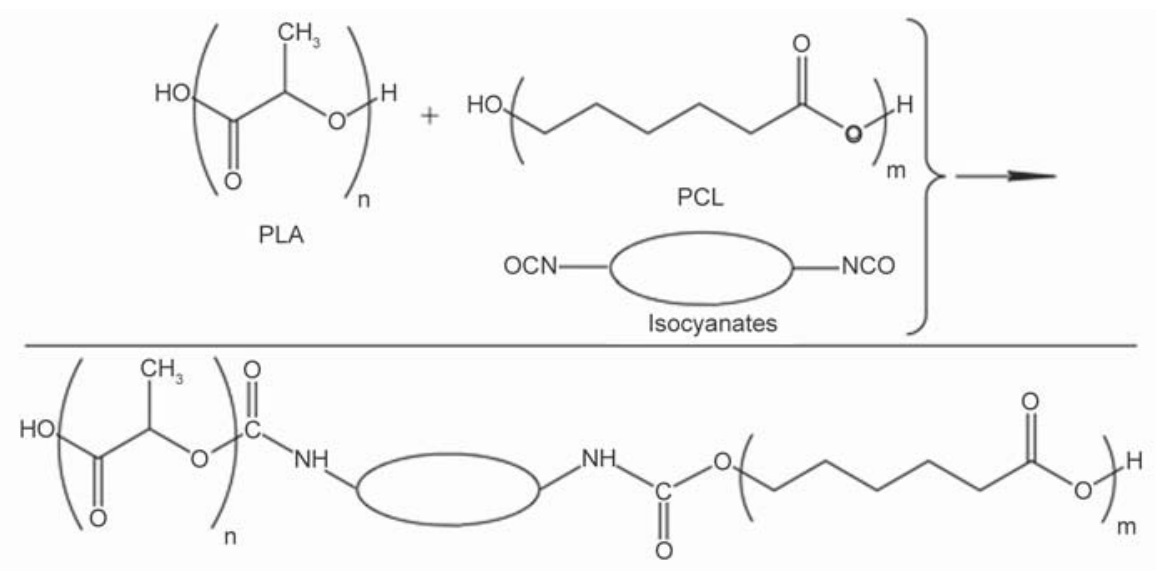

Figure 8. The scheme of reaction between PLA, PCL and isocyanates. Scheme based on [89].

Similar observations were described by Takayama and coworkers [90, 91], which proved that addition of LTI decrease the immiscibility between PLA and PCL. This consequently resulted in an enhanced toughness of the PLA/PCL blends.

Furthermore, in work [92] the effect of lysine triisocyanate content on rheological, mechanical and morphological properties of poly(lactic acid)/poly(butylene succinate) blends was determined. The rheological and morphological analysis confirmed that LTI reacts with PLA and PBS, which resulting in their almost 2-4 times higher impact strength compared to pure PLA.
Gardella et al. [93] proposed the maleic anhydride grafted poly(lactic acid) (PLA-g-MA) as effective compatibilizer of PLA/PCL blends. It was found that replacing of PLA by PLA- $g$-MA reduced dimensions of the PCL domain and enhanced their adhesion to PLA, which have beneficial impact on the mechanical properties (increasing the elongation at break without deterioration of Young's modulus) of PLA/ PCL blends. The scheme of reaction between PLA$g$-MA and PCL is shown in Figure 9.

Shin and Han [94] prepared PLA/PCL blends compatibilized with glycidyl methacrylate (GMA). It was noticed that the addition of GMA is suitable to de-<smiles>CC(C)OC(=O)CCCCCC(C)(C)O[Te]OC(=O)C(C)(O[Ga])C1CC(=O)OC1=O</smiles><smiles>[R10]OC(C)(C(=O)OCCCCC)C(CC(=O)O)C(=O)OCCOC(=O)CCCCCCC</smiles>

Figure 9. Scheme of reaction between PLA-g-MA and PCL. Scheme based on [93]. 
crease the size of PCL phase into PLA/PCL blends, while its impact on interfacial adhesion between phases was not sufficient to transfer the shear stress across the interface. Therefore, to improve the interfacial adhesion in PLA/PCL blends were subsequently treated by electron-beam irradiation. Morphological study and rheological properties indicated that GMA acts as a monomeric plasticizer and a reactive agent at the interface between PLA and PCL phases. Semba and coworkers $[95,96]$ determined the effect of DCP cross-linking on the structure and mechanical properties of PLA/PCL blends. It was found that the diameter of the PCL particles decreased with higher content of DCP during in-situ compatibilization, which results in mechanical properties improvement for the PLA/PCL blend. The results indicated that mechanical properties of PLA/PCL blend in ratio $70 / 30$ modified with $0.3 \mathrm{phr}$ of DCP are comparable to those of popular engineering polymers such as poly(acrylonitrile-butadiene-styrene) copolymer and high-impact polystyrene. On the other hand, the authors pointed that in case of PLA/PCL blends in-situ fiber formation as reinforcing technique is strongly dependent for DCP content. It was observed that higher concentration of DCP made the dispersed phase split, which caused that the ductility of the PCL phase could not be imparted to the PLA matrix. Ma et al. [97] studied the impact of DCP during insitu compatibilization of poly(lactic acid) and poly (butylene adipate-co-terephthalate) (PLA/PBAT) blends. It was proved that using of DCP initiated free radicals in the blends leading to complicated products such as PLA-g-PBAT copolymers, which act like interface compatibilizers between PLA and PBAT. These copolymers enhance mechanical properties, especially toughness of PLA/PBAT blends, such as impact strength or elongation at break parameter. For example, impact strength value for pure PLA/PBAT blend was only $60 \mathrm{~J} / \mathrm{m}$, while for PLA/ PBAT blends after in-situ compatibilization with DCP was $110 \mathrm{~J} / \mathrm{m}$.

Signori et al. [98] modified commercial aliphatic polyesters blend (based on PLA and PBAT) with trade name Ecovio ${ }^{\circledR}$ from BASF using variable content $(0-0.2 \mathrm{wt} \%)$ of dicumyl peroxide. It was found that free radical promoted radical chain branching and cross-linking of PLA/PBAT blends. On the other hand, the results indicated that during processing at high temperature transesterification mechanism may occur in PLA/PBAT blends, which promotes polymer chains rearrangements to form linear, soluble, similar to mixed PLA-PBAT covalently bound chains.

Dong et al. [99] proved that using DCP as cross-linking agent caused branching and partial cross-linking in PHB/PLA blends, which significantly enhanced interfacial adhesion between PLA and PHB phases and improved mechanical properties of the PLA/PHB blends.

For example, it was found that addition of $0.5 \mathrm{wt} \%$ of the DCP to PLA/PHB blend resulting in increased the tensile strength for around $5 \mathrm{MPa}$ and impact toughness by around $30 \%$, comparing to unmodified blend.

Wei and McDonald [100] used different content of DCP (in range: $0.25-1 \mathrm{wt} \%$ ) into PHB/PLA blends. It was noticed that higher concentration of DCP increased cross-link density of PHB/PLA blends and simultaneously decreased their glass transition temperature, melting temperature and degree of crystallinity. This phenomenon is related to fact that during cross-linking some main chain scission also occurred, therefore control of the reaction conditions seems to be crucial to limit polymer degradation. Moreover, it was observed that cross-linking of PHB/ PLA blends with DCP improves their melt strength and thermal stability having beneficial impact on their further thermo-mechanical processing.

Ma et al. [101] examined the poly(3-hydroxybutyrate)/poly(butylene succinate) (PHB/PBS) and poly [(3-hydroxybutyrate)-co-(3-hydroxyvalerate)]/poly (butylene succinate) (PHBV/PBS) blends compatibilized using DCP. The results showed considerable reduction in PBS particle size and a significant improvement of the interfacial adhesion between the PHB (or PHBV) and PBS phases confirmed by microstructure analysis using scanning electron microscopy and transmission electron microscopy. This affects the tensile strength, impact toughness and elongation at break of PHB/PBS and PHBV/PBS blends, which significantly increased for blend in-situ compatibilized with DCP. Schematic diagram of interactions between PHB and PBS in-situ compatibilized with DCP is presented in Figure 10.

Recently, Yang et al. [102] proposed a new two-step method for in-situ compatibilization of PHB/PLA blends. The first step consists of controlled thermal degradation of PHB in an extruder to crotonic acid which results in PHB oligomers with crotonate endgroups suitable for further reactions. As presented in the Figure 11, crotonate end-groups can react with 


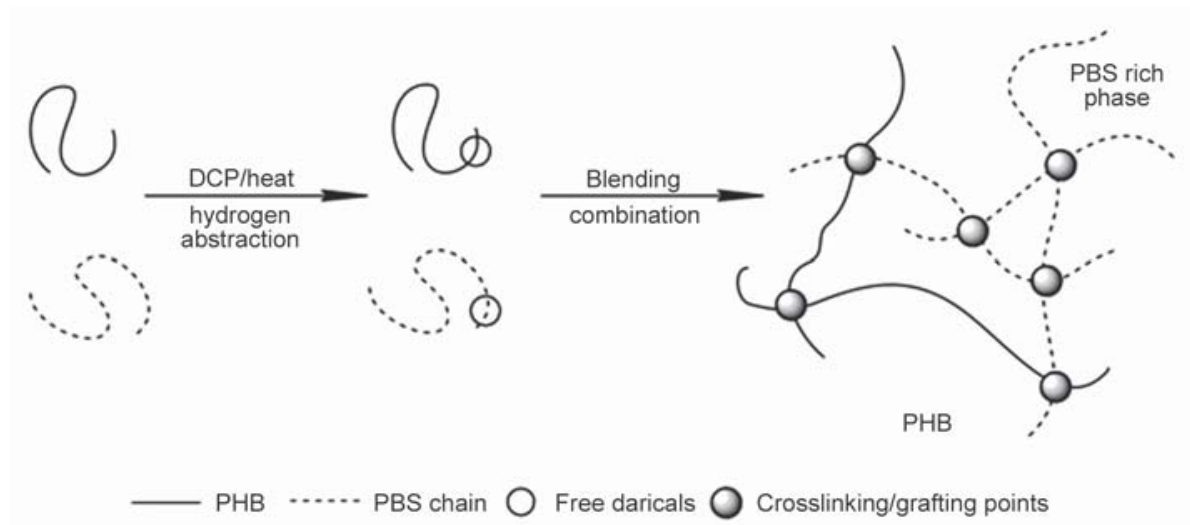

Figure 10. Schematic illustration of the in-situ compatibilization of aliphatic polyester blends using dicumyl peroxide. Scheme is adapted from [101].

methanetriyl carbon in the main chain of PLA, during reactive extrusion in the second step process. This reaction is supported with the 2,5-dimethyl-2,5di(tert-butylperoxy)-hexane organic peroxide with trade name Luperox ${ }^{\circledR} 101$ used as free-radical initiator. The obtained results shown that grafting of degraded PHB into PLA improves its ductility and toughness. For instance, PLA/PHB blends prepared by reactive extrusion showed higher mechanical properties than blends processed via conventional (physical) mixing. For example, when $20 \mathrm{wt} \%$ of thermally degraded PHB was added to PLA matrix, its elongation at break was approximately 66 times higher than that of pure PLA.

Lin et al. [103] compatibilized PLA/PBAT blends using transesterification during melt-extrusion, which was supported by varying concentrations of tetrabutyl titanate (TBT) as catalyst. The morphological studies indicated that incorporation of TBT to PLA/ PBAT blends improve interfacial adhesion between phases, which was also confirmed by enhanced mechanical properties (tensile strength, elongation at break and impact strength). Furthermore, dynamic mechanical analysis showed that using of TBT not

Step I<smiles>CC=CC(=O)OC(C)C(C)C(=O)O</smiles>

Step II
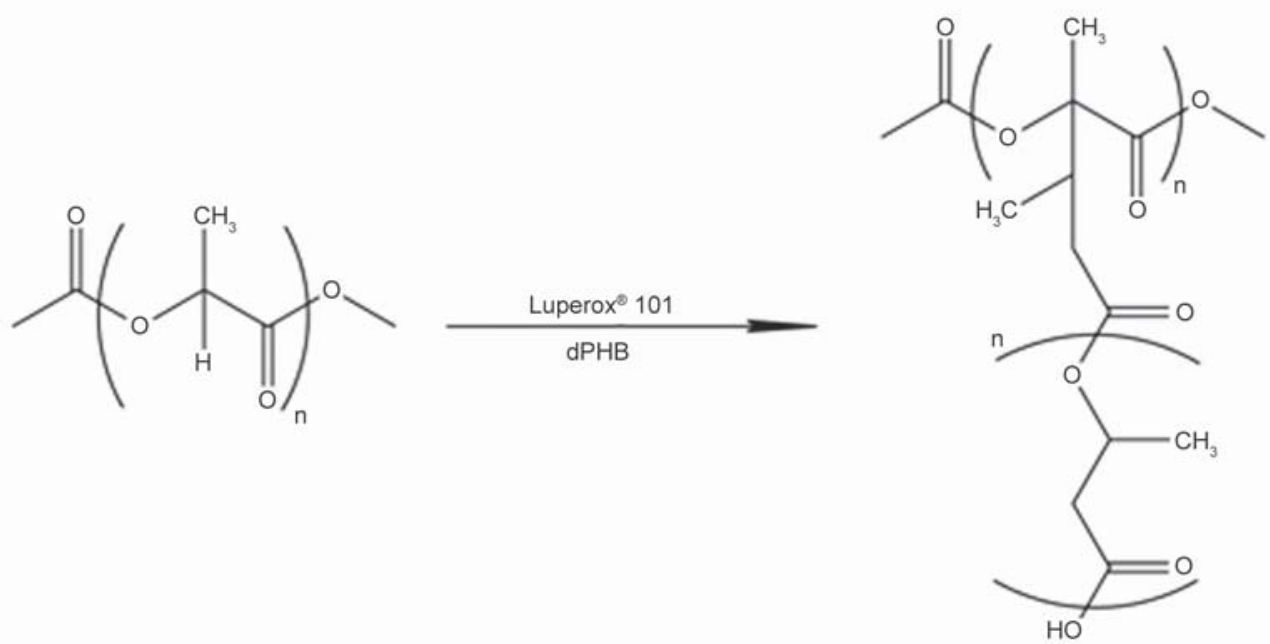

Figure 11. The scheme of two-step method for in-situ compatibilization of PHB/PLA blends. Scheme based on [102]. 
only improved the storage modulus of the blends and glass transition temperature but also promoted the cold crystallization process of PLA.

Coltelli et al. [104] performed transesterification during the melt blending of PLA and PBAT with using of $\mathrm{Ti}(\mathrm{OBu})_{4}$ as a catalyst. The effects of catalyst concentration and reaction duration on structure, rheological, thermal and morphological properties of the PLA/PBAT blends were determined. It was found that use of $\mathrm{Ti}(\mathrm{OBu})_{4}$ and mixing for prolonged time allow effective reduction of the PBAT dispersed phase diameter, which resulted in an improvement of morphological and tensile properties. These results are related to formation of low amount of PLAPBAT copolymers, which act as compatibilizers between phases boundary.

Eslami and Kamal [105] used commercial chain extender with tradename CESA ${ }^{\circledR}$ Extend to modify poly(lactic acid)/poly(butylene succinate-co-adipate) (PLA/PBSA) blends. CESA ${ }^{\circledR}$ Extend is a multifunctional epoxy-based copolymer produced by Clariant. It was noticed that chain extender promoted the development of chain branching in PLA/PBSA blends, while simultaneously its effect on the elastic modulus and elongation at break was negligible. Generally, used chain extender enhanced ductility and melt strength of PLA/PBSA blends, which made this blend more suitable for many end-use applications.

Ojijo and Ray [106] examined the PLA/PBSA blends compatibilized with commercial chain extender Joncryl ${ }^{\circledR}$ produced by BASF. The multifunctional epoxyfunctional chain extender increases molecular weight of prepared blends, which is due to alteration of used components topology from linear structures to long chain branched structures. The reaction mechanism between Joncryl ${ }^{\circledR}$ and aliphatic polyesters is presented in Figure 12. Significant modification of molecular weight distribution led to improvement of melt strength, thermal stability and crystallizability of PLA/ PBSA blends comparing to neat PLA. These observations corresponded with the results presented by Arruda et al. [107] who studied PLA/PBAT blends compatibilized by chain extender Joncryl ${ }^{\circledR}$ (BASF). Recently, Schneider et al. [108] used epoxy functionalized-PLA (EF-PLA) as reactive modifier for PLA/PBAT blends. During reactive extrusion in-situ copolymerization takes place between the epoxy groups present in the EF-PLA modifier and carbonylend groups in PBAT resulting in strong interphase adhesion between blended components and consequently improve mechanical, rheological and morphological properties of PLA/PBAT blends. Epoxy functionalized-PLA can be successfully used as modifier of PLA rheological properties and as a compatibilizer for other biodegradable aliphatic polyesters. Therefore, EF-PLA could be interesting alternative for fully petrochemical based multifunctional epoxybased copolymer as chain extenders.

Current strategies during compatibilization in poly (lactic acid)-based blends were recently summarized in the comprehensive work published by Zeng et al. [109]. The presented solutions could be also used for biodegradable aliphatic polyesters based blends and their composites.

\subsection{Aliphatic polyesters/starch blends}

Dubois and Narayan [110] proposed two different strategies for the reactive compatibilization of

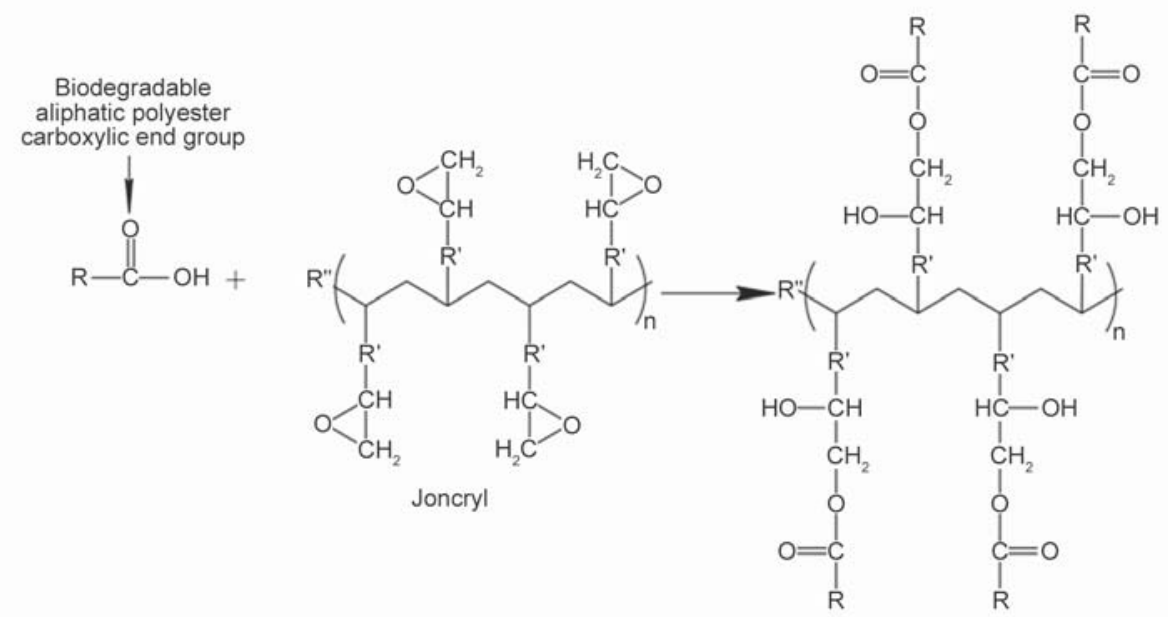

Figure 12. Mechanism of reaction between aliphatic polyesters and multifunctional chain extender Joncryl ${ }^{\circledR}$. Scheme based on [106]. 
PLA/starch and PCL/starch blends, depending on the nature of used aliphatic polyester. Maleic anhydride grafted PLA (PLA-g-MA) obtained through a free radical reaction in reactive extrusion was used as compatibilizer for PLA/starch blends. The morphological analysis, performed using transmittance electron microscopy, showed that PLA-g-MA significantly enhanced the interfacial adhesion between PLA and starch phases. The possible reactions between PLA, starch, maleic anhydride, and free radical initiator (L101) are presented in Figure 13. As could be observed, PLA free radicals induced by the radical initiator are highly reactive with maleic anhydride resulting in PLA-g-MA. Anhydride groups present in PLA- $g$-MA are able to react with the hydroxyl groups of starch leading to ester linkages. Additionally, the hydroxyl groups of starch can form hydrogen bonds with carboxylic groups of the hydrolyzed anhydride and carbonyl groups of PLA, which also improve the compatibility of PLA/starch blends.

In case of PCL/starch blends the authors used PCLgrafted polysaccharide copolymers synthesized via controlled ring-opening polymerization of $\varepsilon$-caprolactone. The obtained results indicate that PCL-grafted polysaccharide copolymers acts like physical compatibilizer, which improved mechanical properties and biodegradation rate of $\mathrm{PCL} /$ starch.

Huneault and Li [111] indicated that reactive blending of PLA-g-MA with thermoplastic starch (TPS) leads to blends with greatly improved ductility. It was found that reaction between components reduces the size of TPS particles and consequently the PLA/TPS blends are more homogeneous. However, higher elongation at break determined for studied blends was observed only when the TPS phases contained $36 \%$ and more glycerol. This phenomenon is<smiles>CC(=O)OC(C)C(=O)OCC#CC(C)OC(C)C</smiles><smiles>CC(=O)C(C)O[C@@H](C)C(=O)OC(C)(OC(C)C)C1CC(=O)OC1=O</smiles>

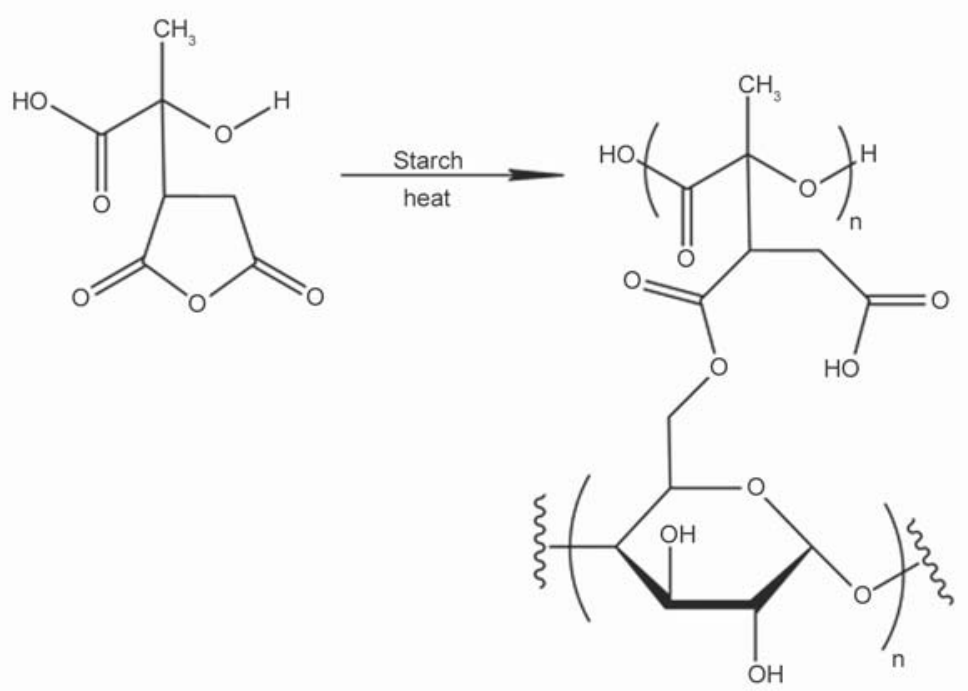

Figure 13. The mechanism of chemical reactions between PLA, starch, MA, and free radical initiator L101. Scheme based on [110]. 
related to too high rigidity of the TPS phase at lower plasticizer content.

As presented above, using of maleic anhydride is a simple and effective way to enhance performance properties of PLA/starch blends. Similar observations have been also reported in works $[112,113]$. Furthermore, Świerz-Motysia et al. [114] showed that biodegradation rate of PLA/TPS blends decreases with an increased content of PLA- $g$-MA as compatibiliz$\mathrm{er}$, which can be associated with its influence on the degree of crystallinity in studied blends.

Kim et al. [115] modified PCL with glycidyl methacrylate (GMA) and maleic anhydride (MA) in the presence of benzoyl peroxide as free radical initiator. It was observed that the molecular weight and polydispersity of glycidyl methacrylate grafted poly ( $\varepsilon$-caprolactone) (PCL-g-GMA) increased with increasing content of the GMA, which indicates that during grafting chain scission reactions did not occur. The possible reactions between GMA and PCL are presented in Figure 14. On the other hand, maleic anhydride during PCL grafting showed opposite tendency. It was found that MA monomer induces the chain scission of PCL during the melt blending, which strongly limits this route and its further applications. The synthesized PCL-g-GMA was subsequently used as reactive compatibilizer in $\mathrm{PCL} / \mathrm{starch}$ blends. The results confirmed that chemical reaction between PCL- $g$-GMA and starch resulting in finer dispersion of the starch in the PCL matrix and improvement of tensile strength of the examined blends.

Suigh et al. [116] synthesized and compared two reactive interfacial agents for starch/PCL blends, glycidyl methacrylate grafted PCL (PCL-g-GMA) and diethyl maleate grafted PCL (PCL-g-DEM). The morphology analysis and the elasticity modulus results indicated that for low content starch in starch/PCL blends, PCL- $g$-DEM has a higher compatibilizing impact than PCL-g-GMA. For blends with a relatively higher starch amount the PCL- $g$-GMA becomes more efficient compatibilizer.

Bossard et al. [117] indicated that reactive functionalization of TPS with formic acid and application of hydroxyl ended polyester oligomers greatly enhanced compatibility between PCL and TPS phases. Examined blends were prepared by one-step reactive extrusion process, which allows their industrial applications in standard processing equipment and limits their thermo-mechanical degradation during prolonged (two- or more steps) processing.

Xiong et al. [118] used epoxidized soybean oil (ESO) as reactive plasticizer to toughen PLA and also as a compatibilizer to improve the interactions between PLA and maleic anhydride grafted starch (starch-gMA). The authors applied starch-g-MA to improve its reactivity with ESO. Consequently, epoxy groups present in ESO are suitable to react with anhydride groups on surface of starch-g-MA and with the end

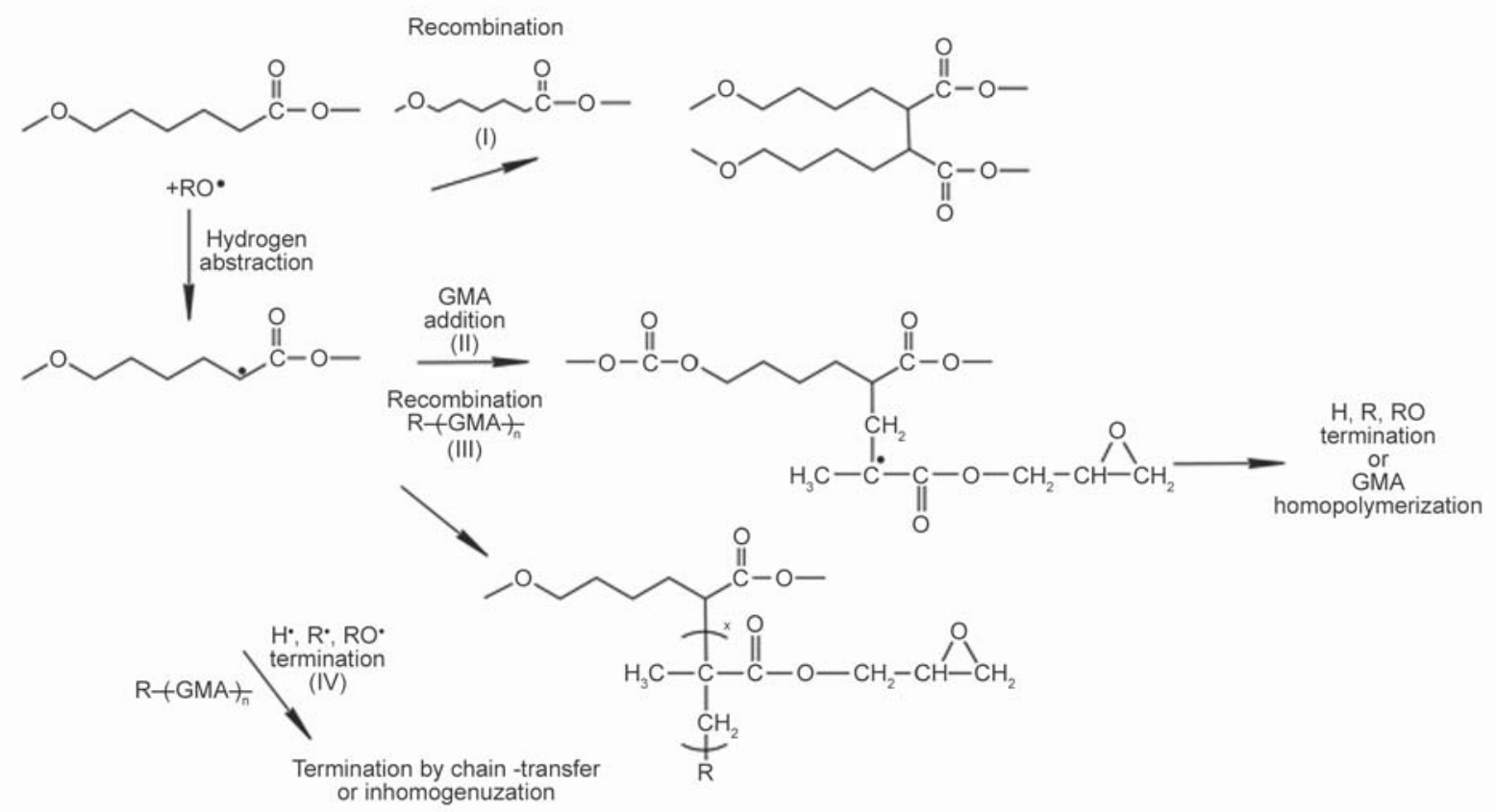

Figure 14. Schematic diagram showing possible reactions during grafting of GMA onto PCL. Scheme based on [115]. 


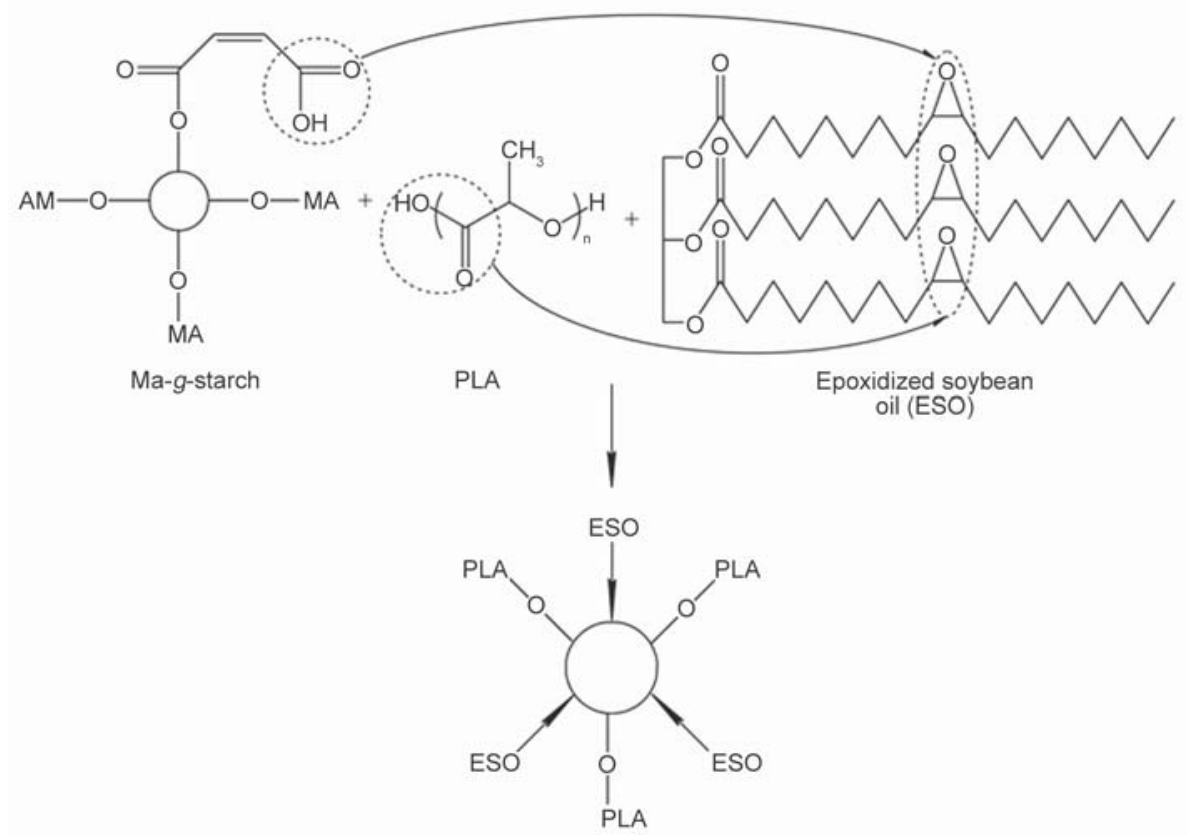

Figure 15. The chemical reaction during compatibilization of PLA/MA-g-starch blends with ESO. Scheme based on [118].

carboxylic acid groups of PLA, resulting in compatible region of PLA, starch- $g$-MA and MA-grafted starch and ESO around modified starch, as presented in Figure 15.

Li and Huneault [119] compatibilized PLA/TPS blends with a multifunctional epoxy-acrylic-styrene copolymer with trade name CESA ${ }^{\circledR}$ Extend. Application of chain extender increased the viscosity of PLA/TPS blends, which improves stress transfer between PLA and TPS phases and leads to significant increase of melt strength and ductility of PLA/TPS blends.

Xiong et al. [120] performed surface modification of starch using bio-based epoxy resins, which allows preparation PLA/starch composites with superior mechanical and thermal properties. It was found that starch modified with the epoxidized itaconic acid or epoxidized cardanol was characterized by higher hydrophobicity (after modification contact angle increased from 44 to $100^{\circ}$ ), which improve interfacial adhesion between used components and tensile properties of PLA/starch blends (tensile strength increased from about 35 to over $50 \mathrm{MPa}$ ). Moreover, differential scanning calorimetry and dynamic mechanical analysis results indicated that surface hydrophobic modification of starch enhanced the crystallization ability of PLA.

Jun [121] used methylene diphenyl diisocyanate (MDI), toluene diisocyanate (TDI), and hexamethylene diisocyanate (HDI) as a reactive compatibilizers of PLA/starch blends. The authors showed that the more effective route of preparation of reactive blends is the two-step process, in which the reactive compatibilizer was added after all other components. It was observed that aliphatic HDI is more effective reactive agent for the PLA/starch blends compared to MDI and TDI.

Karagoz and Ozkoc [122] compatibilized PLA/citric acid modified TPS blends with 1,4-phenylene diisocyanate. The combined usage of 1,4-phenylene diisocyanate and modification of TPS by citric acid reduced the particle size of TPS and enhanced its dispersion into PLA matrix, resulting in significant improvement of the mechanical properties of studied blends.

The present state of knowledge shows that the compatibilization strategies used for aliphatic polyesters blends and aliphatic polyesters/starch blends are usually very similar and developing in the same directions. Furthermore, current research in this field indicate that these types of fully biodegradable blends are more often used as filaments in 3D printing [123, 124]. The example of extrusion line dedicated for technology of 3D printing filaments production is presented in the Figure 16.

In our opinion this trend will grow in near future, which is related to versatile applications of $3 \mathrm{D}$ printing, such as industrial design, automobiles, architecture, mechanical engineering, biomedical engineering, etc. However, according to our best knowledge, $3 \mathrm{D}$ printing filaments prepared by reactive extrusion are currently poorly described in the literature [125]. 


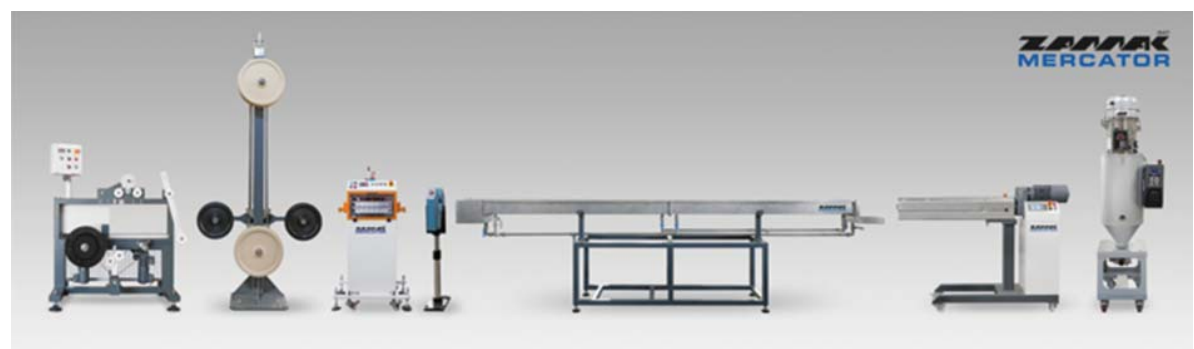

Figure 16. Extrusion line for production of 3D printer filament (reprinted with permission from Zamak Mercator Sp. z o.o., Skawina, Poland, http://www.zamakmercator.pl/)

\subsection{Aliphatic polyester/natural rubber blends} Preparation of polymer blends from semi-crystalline thermoplastic polymers and amorphous elastomers creates a possibility to obtain thermoplastic elastomers [126-128]. In comparison to conventionally cross-linked elastomers, using of thermoplastic elastomers has number of benefits, such as possibility of prepare them from commercially available components (thermoplastics and elastomers), which allows obtained products with various properties and versatile industrial applications. Furthermore, thermoplastic elastomers can be processed and recycled using conventional methods (e.g. extrusion, injection molding, grinding, granulation, etc.), which have beneficial influence on the price of final product. Above mentioned factors caused that searching for new thermoplastic elastomers or thermoplastic/elastomer blends prepared via melt-compounding enjoys currently growing interest among researchers [129-131]. It seems that promising route during studies in this field are aliphatic polyester/elastomers blends with unique and specific properties, such as full or partial biodegradability, shape-memory or shrinkability [132-134]. Base on biodegradability of this type of materials, in this subchapter, we were focused mainly on aliphatic polyester/natural rubber blends.

Zhang et al. [135] used epoxidized natural rubber (ENR) with different epoxidation level (ENR20 $20 \mathrm{~mol} \%$ and ENR50 - $50 \mathrm{~mol} \%$ ) as toughening agents for poly(lactic acid). Comparing to pure PLA, the impact strength of the $20 \mathrm{wt} \%$ PLA/ENR20 and PLA/ENR50 blends increased to 6-fold and 3-fold, respectively. On the other hand, introduction of ENR reduced the tensile strength and hindered the crystallization of PLA due to cross-linking between ENR and PLA molecular chains. It was observed that PLA/ ENR50 blend showed higher melt viscosity, storage and loss modulus, comparing to PLA/ENR20, which confirmed that with higher epoxidation level in ENR increase its cross-linking with PLA. The mechanism of this reaction is presented in Figure 17.

Epoxidized natural rubber was also successfully used as reactive compatibilizer for poly(3-hydroxybutyrate) and aliphatic polyesters blends [136-138]. Jaratrotkamjorn et al. [139] modified PLA via meltblending with natural rubber (NR), epoxidized natural rubber (ENR), and poly(methyl methacrylate) grafted natural rubber grafted (NR-g-PMMA). It was observed that smaller particles of ENR and NR-gPMMA in the blends indicated higher miscibility with PLA than virgin NR. However, under the studied conditions the particles of functionalized natural rubber with more structural rigidity compared to pure NR, were too small to promote toughening of PLA. The presented results showed that molecular weight

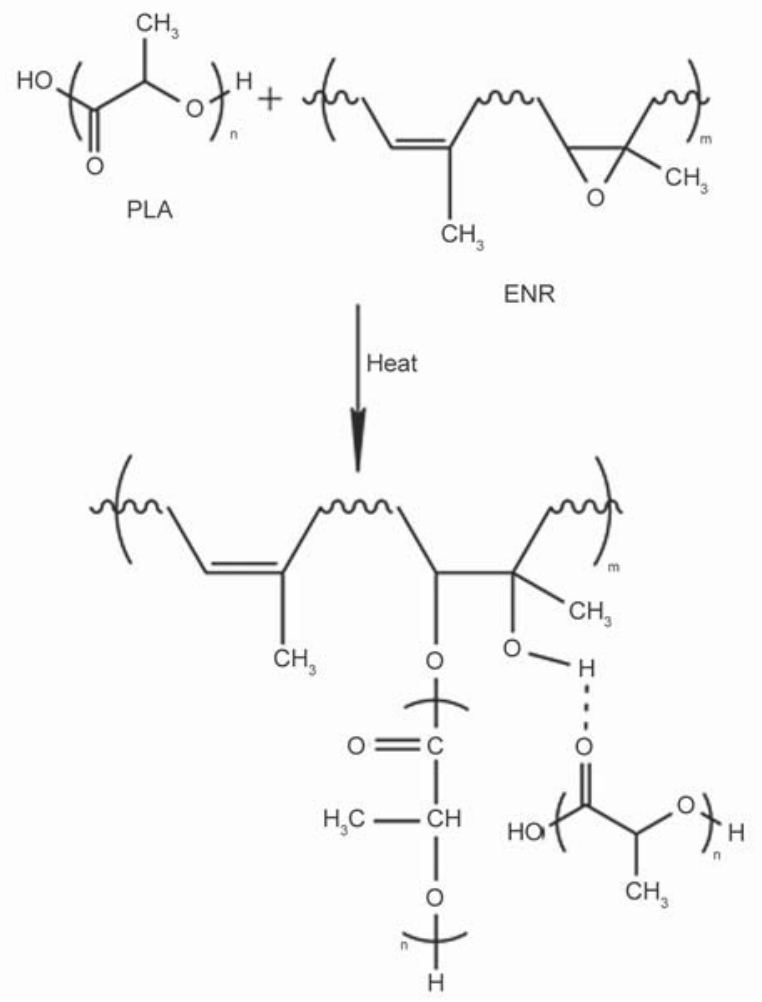

Figure 17. The mechanism of reaction between epoxidized natural rubber (ENR) and PLA. Scheme based on [135]. 
and viscosity of natural rubber plays a major role in the mechanical properties and morphology of the PLA/NR blends in ratio 90/10, therefore pure NR (especially masticated NR) was more effective additive than ENR or NR-g-PMMA to raise the toughness of PLA matrix.

Zhang et al. [140] proved that thermo-mechanically sheared NR significantly enhanced the ductility of PLA. It was observed that $3 \mathrm{wt} \%$ of thermo-mechanically sheared NR (for $10 \mathrm{~min}$, at $145^{\circ} \mathrm{C}$ ) added to PLA improved its elongation at break (196.2 vs. $16.3 \%$ for pure PLA) and toughness (77.5 vs. $8.8 \mathrm{MJ} / \mathrm{m}^{3}$ for pure PLA), without noticeable loss in its tensile strength. This phenomenon is related to formulation of carbonyl groups in NR chains after hot shearing, which enhance the NR polarity resulting in higher compatibility between NR and PLA.

Juntuek et al. [141] proposed using of a glycidyl methacrylate grafted natural rubber (NR-g-GMA) as effective compatibilizer for PLA/NR blends. The effects of content and \% grafting of NR-g-GMA on mechanical properties of PLA/NR blends were evaluated. It was noticed that increasing NR-g-GMA content (up to $1 \mathrm{wt} \%$ ) and increasing $\%$ grafting of NR-g-GMA (up to $4.35 \%$ ) have beneficial influence on impact strength and elongation at break of studied blends.

Zhang et al. [142] used poly(butyl acrylate) grafted natural rubber (NR-g-PBA) as toughening agent of PLA. The morphology assessment showed that the spherical particles dispersed phase appearing in the PLA/pure NR blend, while the in case of PLA/NR$g$-PBA sample the surface was more homogenous. This indicates that the compatibility between NR and PLA is significantly improved by NR-g-PBA, which resulting in its more efficient toughening effect on PLA comparing to pure NR.

Mohammad et al. [143] proved that PLA/NR blends can be successfully compatibilized with small amount
(3 phr) of maleic anhydride grafted PLA (PLA-gMA) and maleic anhydride grafted NR (NR-g-MA). The authors pointed out that addition of PLA-g-MA and NR-g-MA reduces the amount of gaps and voids between PLA and NR, which is due to higher interfacial adhesion between these two phases.

Huang et al. [144] studied the effect of dicumyl peroxide content on morphology, mechanical, thermal and rheological properties of PLA/NR blends. The obtained results showed that dicumyl peroxide could increase the compatibility of PLA and NR, which corresponded with the results of mechanical testing and thermal analysis. This is due to partial crosslinking of PLA/NR blends during melt processing with DCP, as presented in Figure 18.

It was noticed that using less than $0.5 \mathrm{wt} \%$ of DCP in PLA/NR blends, generally decreased their complex viscosity. On the other hand, for blends with DCP content up to $0.5 \mathrm{wt} \%$, opposite trend was observed. This allows simple tailoring the rheological properties of PLA/NR blends before further processing.

Dynamic curing of PCL/NR blends using DCP as initiator was also performed by Chen et al. [145]. Based on morphological studies and dissolution/ swelling experiments the authors indicated that dynamical curing of PLA/NR blends with DCP resulting in formulation of cross-linked natural rubber continuous phase.

Chen et al. [146] studied bio-based NR/PCL shape memory polymer blends. The results they presented showed that the use of DCP caused cross-linking of NR/PCL blends and also formulation of NR-co-PCL copolymer, which acts as a compatibilizer in NR/ PCL blends. Improved compatibility of NR/PCL was confirmed by infrared spectroscopy, scanning electron microscopy analyses and the mechanical properties measurements. Similar observations were described in work [147], wherein the authors proved that increasing emissions of volatile organic compounds

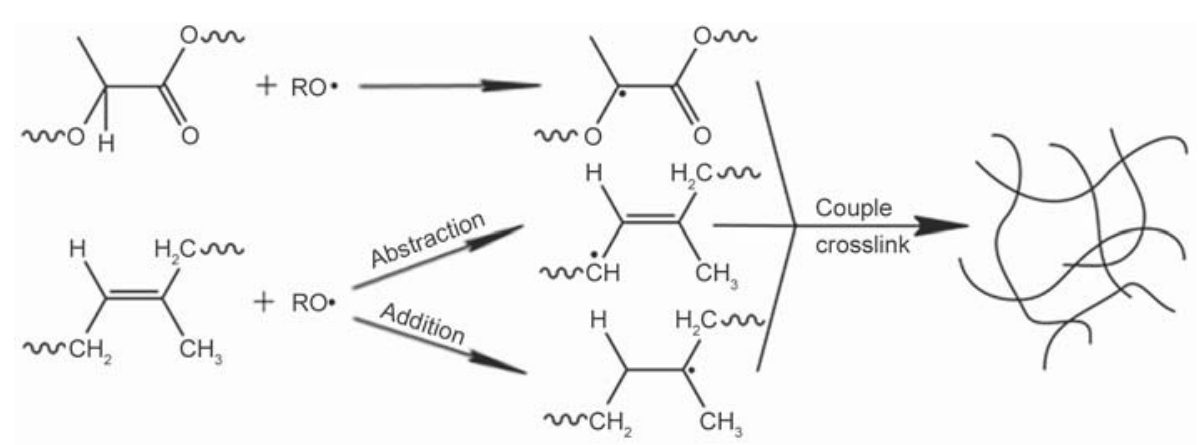

Figure 18. The possible reactions during melt processing of PLA/NR blends with DCP. Scheme based on [144]. 
from NR/PCL blends indicate deterioration of their mechanical properties.

Mishra and coworkers [148, 149] obtained PCL/ ENR blends cured with dicumyl peroxide. The authors indicated that cross-linking bonds formed in PCL/ENR blends act as a memory point during shrinkage, which improves heat shrinkability and the final mechanical properties of PCL/ENR blends.

Wang et al. [150] performed dynamic curing to prepare bio-based thermoplastic vulcanizates composed of PLA and ENR. The results showed that impact toughness of obtained thermoplastic vulcanizates depended on the PLA/ENR weight ratio, phase morphology, and DCP content. It was noticed that dynamically cured PLA/ENR blend in ratio $60 / 40$ was characterized nearly 15 times higher impact strength than for pure PLA.
In most reported studies, application of compatibilized for bio-based blends results in enhancement of compatibility and mechanical properties, which can be seen in Table 3.

In Table 4 commonly used compatibilizers for biobased blends are presented. As it can be noticed, various types of chemical compounds can be applied, such as: isocyanates, esters, peroxides, acid anhydrides and grafted polymers.

\section{Composites based on biodegradable polyesters}

Progress in reactive extrusion of bio-based polymer blends is a good starting point for preparation of novel composites materials with biodegradable matrices. At present, the most common used biodegradable polyesters for fabrication of thermoplastic biocomposties

Table 3. Comparison of properties of bio-based blends compatibilized by various chemical compounds

\begin{tabular}{|c|c|c|c|c|c|c|c|c|}
\hline \multirow[b]{2}{*}{$\begin{array}{l}\text { Type of } \\
\text { blend }\end{array}$} & \multicolumn{2}{|c|}{ Polymer matrix } & \multicolumn{2}{|c|}{ Compatibilizer } & \multirow[b]{2}{*}{ Preparation methods } & \multicolumn{2}{|c|}{ Mechanical properties } & \multirow[b]{2}{*}{ Ref. } \\
\hline & Blend & Ratio & Type & $\begin{array}{c}\text { Content } \\
{[w t \%]}\end{array}$ & & $\begin{array}{c}\text { Tensile } \\
\text { strength } \\
\text { [MPa] }\end{array}$ & $\begin{array}{c}\text { Elongation } \\
\text { at break } \\
{[\%]}\end{array}$ & \\
\hline \multirow{12}{*}{ 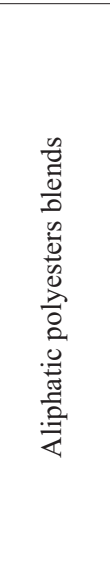 } & PLA/PCL & $80 / 20$ & GMA & 3.00 & $\begin{array}{l}\text { Twin-screw, } 150 \mathrm{rpm}, 160-190^{\circ} \mathrm{C} \text {; } \\
\text { Electron beam irradiation }\end{array}$ & $22.0-55.0$ & $5-33$ & [92] \\
\hline & \multirow{5}{*}{ PLA/PBAT } & \multirow{5}{*}{$80 / 20$} & \multirow{11}{*}{ DCP } & 0.05 & \multirow{5}{*}{$\begin{array}{l}\text { Internal mixer, } 50 \mathrm{rpm}, 170^{\circ} \mathrm{C} \text {; } \\
\text { Compression moulding, } 10 \mathrm{MPa} \text {, } \\
170^{\circ} \mathrm{C}\end{array}$} & 42.1 & 213 & \multirow{5}{*}[95]{} \\
\hline & & & & 0.10 & & 43.5 & 309 & \\
\hline & & & & 0.20 & & 44.6 & 277 & \\
\hline & & & & 0.50 & & 45.9 & 244 & \\
\hline & & & & 1.00 & & 46.0 & 29 & \\
\hline & \multirow{3}{*}{ PHBV/PBS } & \multirow{3}{*}{$80 / 20$} & & 0.20 & \multirow{3}{*}{$\begin{array}{l}\text { Internal mixer, } 40 \mathrm{rpm}, 170^{\circ} \mathrm{C} \text {; } \\
\text { Compression moulding, } 10 \mathrm{MPa} \text {, } \\
170^{\circ} \mathrm{C}\end{array}$} & 29.0 & 200 & \multirow{6}{*}{ [99] } \\
\hline & & & & 0.50 & & 28.0 & 400 & \\
\hline & & & & 1.00 & & 27.0 & 350 & \\
\hline & \multirow{3}{*}{ PHB/PBS } & $80 / 20$ & & \multirow{3}{*}{0.50} & \multirow{3}{*}{$\begin{array}{l}\text { Internal mixer, } 40 \mathrm{rpm}, 170^{\circ} \mathrm{C} \text {; } \\
\text { Compression moulding, } 10 \mathrm{MPa} \text {, } \\
170^{\circ} \mathrm{C}\end{array}$} & 40.0 & 4 & \\
\hline & & $70 / 30$ & & & & 38.0 & 11 & \\
\hline & & $50 / 50$ & & & & 37.0 & 15 & \\
\hline \multirow{6}{*}{ 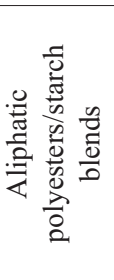 } & \multirow{6}{*}{ PCL/starch } & \multirow{6}{*}{$80 / 20$} & \multirow{3}{*}{ PCL- $g$-DEM } & 1.00 & \multirow{6}{*}{ Internal mixer, $80 \mathrm{rpm}, 170^{\circ} \mathrm{C}$} & 11.1 & 402 & \multirow{6}{*}{ [115] } \\
\hline & & & & 2.00 & & 10.9 & 385 & \\
\hline & & & & 5.00 & & 11.0 & 380 & \\
\hline & & & \multirow{3}{*}{ PCL-g-GMA } & 1.00 & & 9.2 & 357 & \\
\hline & & & & 2.00 & & 9.6 & 343 & \\
\hline & & & & 5.00 & & 11.7 & 432 & \\
\hline \multirow{9}{*}{ 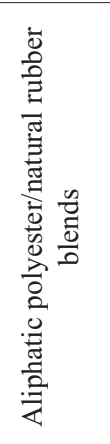 } & \multirow{8}{*}{$\mathrm{PLA} / \mathrm{NR}$} & $1 / 99$ & \multirow{3}{*}{-} & \multirow{3}{*}{-} & & 81.4 & 32 & \\
\hline & & $3 / 97$ & & & Internal mixer, $60 \mathrm{rpm}, 170^{\circ} \mathrm{C}$ & 76.9 & 196 & [139] \\
\hline & & $10 / 90$ & & & & 57.4 & 137 & \\
\hline & & $90 / 9$ & & 1.00 & & 27.5 & 159 & \\
\hline & & $90 / 7$ & NR-g-GMA & 3.00 & $\begin{array}{l}\text { Internal mixer, } 60 \mathrm{rpm}, 170^{\circ} \mathrm{C} \text {; } \\
\text { Coulding } 165^{\circ} \text { ression }\end{array}$ & 26.7 & 110 & {$[140]$} \\
\hline & & $90 / 5$ & & 5.00 & & 26.6 & 88 & \\
\hline & & $05 / 5$ & PLA-g-MA & 300 & Twin-screw extruder, $100 \mathrm{rpm}$, & 31.0 & 2 & {$[142]$} \\
\hline & & $95 / 5$ & NR-g-MA & 3.00 & $160-180^{\circ} \mathrm{C}$ & 25.0 & 2 & {$[142]$} \\
\hline & PCL/NR & $50 / 50$ & DCP & 1.00 & $\begin{array}{l}\text { Internal mixer, } 60 \mathrm{rpm}, 160^{\circ} \mathrm{C} \text {; } \\
\text { Compression moulding, } 180^{\circ} \mathrm{C}\end{array}$ & 9.3 & 910 & [147] \\
\hline
\end{tabular}


Table 4. Chemical structure of compatibilizers commonly used for bio-based blends

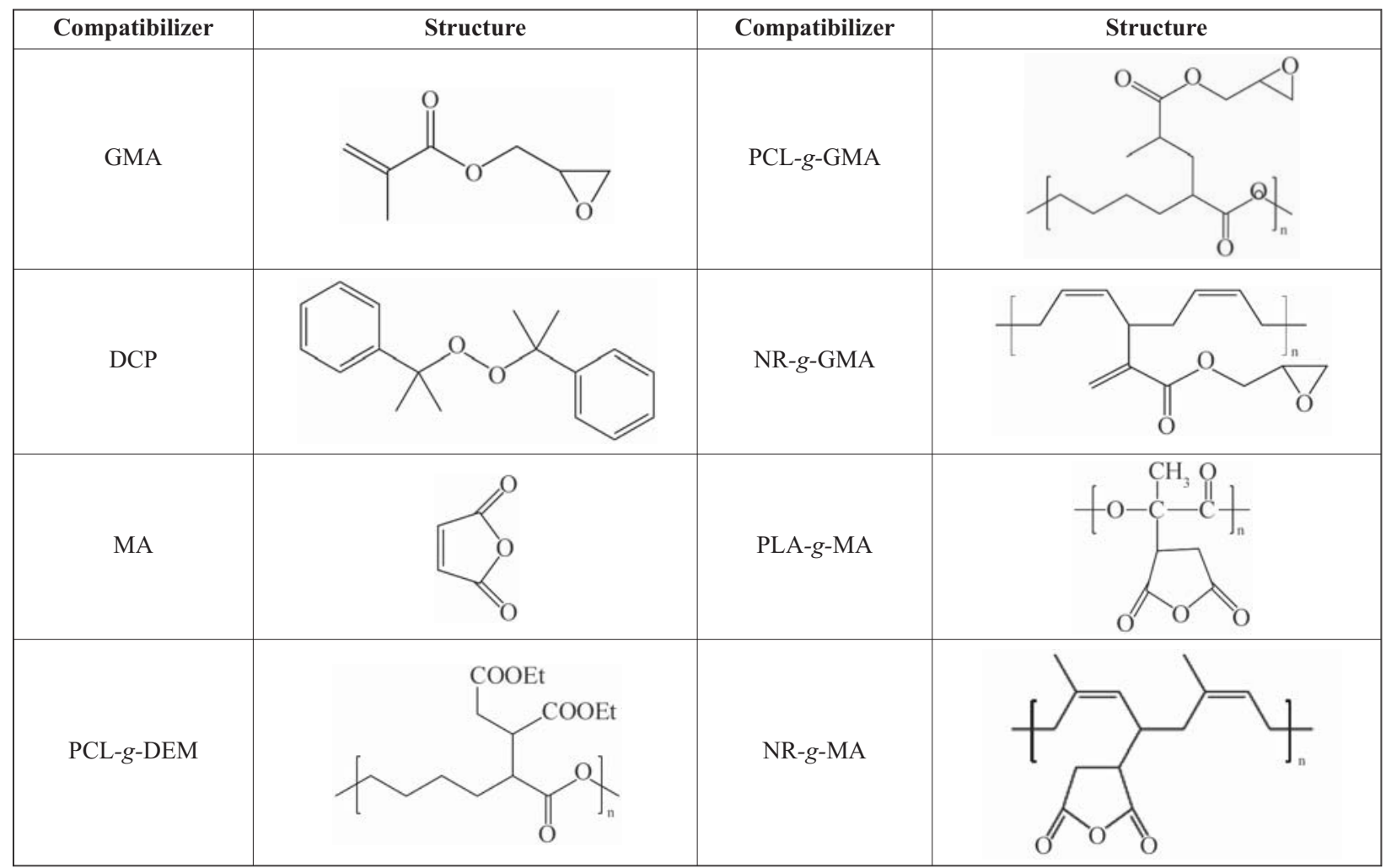

is poly(lactic acid) (PLA). Recently, Dhar et al. [151] evaluated the morphology, mechanical and thermal properties of poly(lactic acid)/cellulose nanocrystals PLA/CNC biocomposites in-situ compatibilized with PLA chains grafted onto CNC surface (CNC-gPLA). The biocomposites were obtained during single step reactive extrusion process carried out in a co-rotating twin screw extruder. The grafting mechanism of each steps of reactions occurring during reactive extrusion process (initiation, propagation and termination) are illustrated in Figure 19. As has been proved by authors, the chemical cross-linking provoke by addition DCP led to efficient transfer of mechanical properties of cellulose nanocrystal (CNC) to PLA matrix. Compared to pure PLA, the improvement of the tensile strength by $\sim 40 \%$ and Young's modulus by $\sim 49 \%$ have been reported. Moreover, it was found that the recycling of PLA/CNC biocomposites does not affect drastically the molecular weight, thermal, crystallization and mechanical properties of the studied materials, which indicated that obtained biocomposites does not easily recycled and reused for multiple cycles.

Rytlewski et al. [152] have investigated the adhesion between polylactide (PLA) and flax or hemp fibres after their interphase cross-linking using DCP. A single-screw extruder was used to fabricate the biocomposites. Authors used different techniques to study properties of developed composites such as differential scanning calorimetry, tensile and impact strength tests, dynamic mechanical analysis and scanning electron microscopy. Obtained results indicated that in this particular case the use of DCP is an ineffective way to improve interfacial adhesion of composites based on PLA homopolymer and flax or hemp fibres, which could be due to the micrometric (not nanometric) size of used fibers. Furthermore, the lack of DCP effectiveness to improve matrix/filler adhesion could be related to complexity of chemical reactions between used components (natural fibers, PLA matrix and DCP). Especially taken into account that, diversity of physico-chemical properties of natural fibers/fillers has significant impact on the interfacial interactions in biocomposites [153-155].

Sajna et al. [156] evaluated the impact of nanoclay and glycidyl methacrylate grafted poly(lactic acid) (PLA- $g$-GMA) on the thermal and flammability properties of PLA/banana fiber biocomposites. Thermogravimetric analysis, UL-94 horizontal burning test and cone calorimetry results indicated that the PLA$g$-GMA and nanoclay in PLA/banana fiber biocomposites enhance their thermal stability and resistivity towards the flame due to formation of protective surface layer towards the flame. 


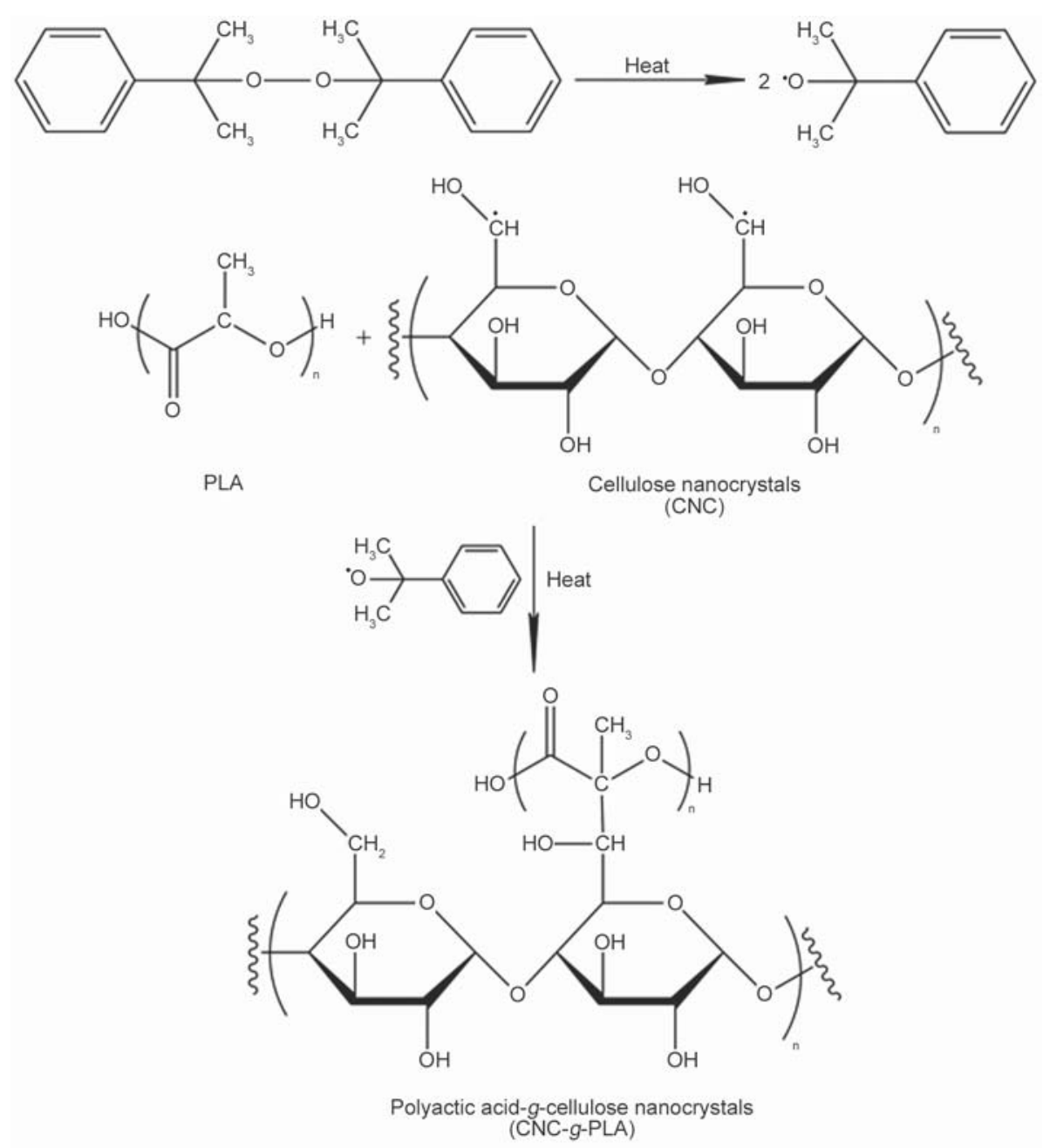

Figure 19. Mechanism of formulation of CNC- $g$-PLA during reactive extrusion. Scheme based on [151].

Mirzadeh et al. [157] modified poly(lactic acid)/ poly(butylene succinate-co-adipate) (PLA/PBSA) blends with CESA ${ }^{\circledR}$ Extend chain extender and nanoclay Cloisite 30B. The authors proved that the presence of nanoclay in PLA/PBSA blends has strong impact on the mechanical properties of the obtained biocomposites, while its barrier properties allow controlling the local concentration of chain extender in the PLA phase. Addition of nanoclay Cloisite 30B to PLA/PBSA increased blends viscosity, while more visible effect of improvement was noticed for blends with higher PBSA content.

Dai et al. [158] studied the effect of epoxidized soybean oil (ESO) as reactive plasticizer on selected properties of PLA filled with microcrystalline cellulose (MCC). It was observed that during melt blending of ESO with PLA and MCC, ESO reacts with MCC particles and is accumulated on their surface. The results showed that the formation of a thin ESO layer on MCC particles surfaces enhanced interfacial adhesion between PLA and MCC phases, which resulted in superior toughness of studied biocomposites. The elongation and impact strength of PLA/ MCC biocomposites were finally improved up to $38.5 \%$ and $31.7 \mathrm{~kJ} / \mathrm{m}^{2}$. Similar observations were described by Khoo and Chow [159], who confirmed that addition of ESO significantly improved impact strength of poly(lactic acid)/sugarcane bagasse fiber biocomposites.

Dai et al. [160] synthesized highly reactive epoxidized citric acid (ECA), which was subsequently used as bio-based compatibilizer of PLA/MCC biocomposites. The steps during synthesis and the chemical formula of ECA are presented in Figure 20. The obtained results revealed that low content $(1-5 \mathrm{wt} \%)$ of ECA in PLA/MCC biocomposites promoted interfacial adhesion between PLA and MCC, which has beneficial impact on their flexural property.

Dogu and Kaynak [161] proved that application of 3 wt \% PLA- $g$-MA copolymer in PLA/MCC biocomposites improved the distribution uniformity of MCC particles and also adhesion between PLA matrix and 


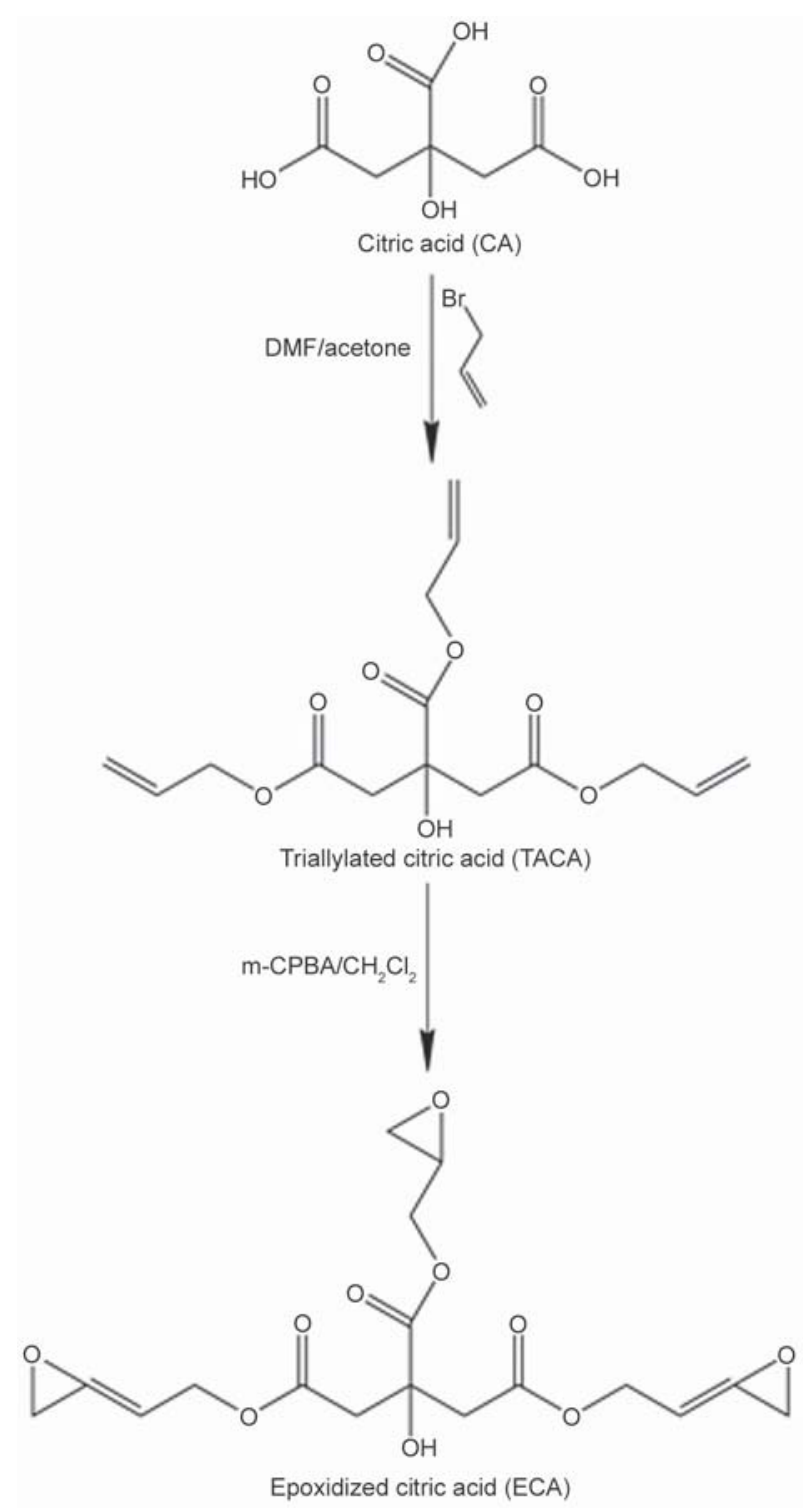

Figure 20. Reaction steps during synthesis of ECA. Scheme based on [160].

MCC filler. This resulted in the enhancement of fracture toughness of the studied biocomposites, which increased for $22 \%$ comparing to sample without PLA-g-MA as a compatibilizer.

Generally, majority of reported studies based on the compatibilization of PLA-based biocomposites via reactive extrusion resulted in significant enhancement of mechanical performance, which can be seen in Table 5.

The published data indicated that among various commercial available biodegradable aliphatic polyesters, poly(E-caprolactone) (PCL) homopolymer has been the second most important polymer used for preparation of biocomposties. de Campos et al. [166] prepared poly( $\varepsilon$-caprolactone)/thermoplastic starch (PCL/TPS) blends reinforced with sisal fibers bleached with sodium-hydroxide followed by hydrogen peroxide treatment. Morphology, water absorption and the biodegradability of PCL/TPS/sisal fibers biocomposites as a function of sisal fibers content were evaluated. It was noticed that sisal fibers were well dispersed in PCL/TPS matrix, while the $10 \mathrm{wt} \%$ of sisal fibers increased crystallinity and lower water absorption capacity of PCL/TPS/sisal fibers biocomposites. Furthermore, the authors indicated that incorporation of sisal fibers might allow control biodegradation rate of PCL/TPS matrix in a more predictive manner.

Kalambur and Rizvi [167-169] extensively investigated PCL/starch biocomposites fabricated by two steps performed in a single screw extrusion process, which is very promising from industrial application point of view. As demonstrated in Figure 21, the first step has been related to oxidation of starch by the replacement of hydroxyl groups by carboxyl or carbonyl groups and subsequently in second step, partially oxidized starch react with PCL. In both steps, during reaction Fenton's reagent (hydrogen peroxide with iron and copper catalysts) was used as the oxidizing/cross-linking agent. The authors developed highly filled PCL/starch biocomposites modified with MMT nanoclay, which were characterized by mechanical properties (e.g. toughness and elongation at break) similar to pure PCL. This opens new possibilities of PCL/starch biocomposites further applications.

Polyhydroxyalkanoates such as poly(3-hydroxybutyrate) (PHB) and random copolymers with poly(3hydroxyvalrate) and other commercial aliphatic polyesters have been also intensively studied to design composites based on biodegradable matrix. Recently, green biocomposites based on poly(3-hydroxybutyrate-co-3-hydroxyvalerate) (PHBV) and softwood Kraft lignin have been prepared during reactive extrusion in presence of DCP as free radical initiator [170]. The authors have reported that addition of DCP enhanced interfacial adhesion between PHBV and softwood Kraft lignin, due to the formation of lignin$g$-PHBV copolymer and decrease of crystallinity of PHBV in biocomposites. It is well known that during heating the DCP decomposes into cumyloxy radicals, which in majority form methyl radicals by $\beta$-scission. During reactive extrusion, these strong radicals are able to abstract hydrogen atoms from both PHBV and lignin, and consequently initiate grafting leading to lignin- $g$-PHBV copolymer, as presented in Figure 22. 
Table 5. Routes of PLA-based biocomposites compatibilization via reactive extrusion

\begin{tabular}{|c|c|c|c|c|c|c|c|}
\hline Filler & $\begin{array}{l}\text { Content } \\
{[w t \%]}\end{array}$ & Compatibilizer & $\begin{array}{c}\text { Content } \\
\text { [wt } \%]\end{array}$ & Preparation methods & $\begin{array}{c}\text { Tensile } \\
\text { strength } \\
\text { [MPa] }\end{array}$ & $\begin{array}{c}\text { Elongation } \\
\text { at break } \\
{[\%]}\end{array}$ & Ref. \\
\hline- & - & \multirow{5}{*}{ Dicumyl peroxide } & \multirow{2}{*}{0.00} & \multirow{5}{*}{$\begin{array}{c}\text { Single screw, } \\
170 / 180 / 190 / 190^{\circ} \mathrm{C}\end{array}$} & $72.2 \pm 0.4$ & $5.4 \pm 0.5$ & \multirow{5}{*}[152]{} \\
\hline \multirow{2}{*}{ Flax fiber } & \multirow{4}{*}{10} & & & & $66.4 \pm 1.3$ & $3.9 \pm 0.5$ & \\
\hline & & & 0.50 & & $67.0 \pm 0.7$ & $3.8 \pm 0.3$ & \\
\hline \multirow{2}{*}{ Hemp fiber } & & & 0.00 & & $66.9 \pm 0.6$ & $3.7 \pm 0.4$ & \\
\hline & & & 0.50 & & $67.3 \pm 1.3$ & $3.6 \pm 0.4$ & \\
\hline- & - & \multirow{5}{*}{ Epoxidized soybean oil } & \multirow{2}{*}{0.00} & \multirow{5}{*}{$\begin{array}{c}\text { Twin screw, } 40 \mathrm{rpm}, \\
175^{\circ} \mathrm{C}\end{array}$} & $67.0 \pm 2.2$ & $3.5 \pm 0.3$ & \multirow{5}{*}[158]{} \\
\hline $\mathrm{MCC}$ & 20 & & & & $57.3 \pm 1.5$ & $2.9 \pm 0.6$ & \\
\hline- & - & & \multirow{3}{*}{10.00} & & $66.8 \pm 1.2$ & $3.3 \pm 0.5$ & \\
\hline MCC & \multirow{2}{*}{20} & & & & $35.8 \pm 0.7$ & $21.2 \pm 3.4$ & \\
\hline MMCC & & & & & $31.4 \pm 2.4$ & $27.3 \pm 1.4$ & \\
\hline \multirow{4}{*}{$\begin{array}{l}\text { Wood pulp } \\
\text { fiber }\end{array}$} & 0 & \multirow{4}{*}{$\begin{array}{c}\mathrm{N} \text {-(o-phenylene)-dimalemide }+ \\
\text { 2,2'dithiobis(benzothiazole) }\end{array}$} & 0.00 & \multirow{4}{*}{$\begin{array}{c}\text { Twin screw, } 120 \mathrm{rpm} \text {, } \\
180-195^{\circ} \mathrm{C}\end{array}$} & $63.0 \pm 1.1$ & $3.0 \pm 0.1$ & \multirow{4}{*}{ [162] } \\
\hline & 20 & & 0.00 & & $58.7 \pm 0.5$ & $2.0 \pm 0.1$ & \\
\hline & 20 & & $0.75+0.1$ & & $61.2 \pm 0.6$ & $1.8 \pm 0.1$ & \\
\hline & 0 & & $0.75+0.1$ & & $65.1 \pm 1.1$ & $2.8 \pm 0.1$ & \\
\hline \multirow{5}{*}{$\begin{array}{l}\text { Soy protein } \\
\text { concentrate }\end{array}$} & 0 & \multirow{5}{*}{ PLA- $g$-MA } & 0.00 & \multirow{5}{*}{$\begin{array}{c}\text { Twin screw, } \\
90 / 100 / 130 / 145 / 160 / \\
160 / 160 / 155100^{\circ} \mathrm{C}\end{array}$} & $65.1 \pm 0.6$ & $3.6 \pm 0.1$ & \multirow{5}{*}{ [163] } \\
\hline & \multirow{4}{*}{30} & & 0.00 & & $44.7 \pm 0.5$ & $1.5 \pm 0.1$ & \\
\hline & & & 1.00 & & $48.6 \pm 0.7$ & $1.7 \pm 0.0$ & \\
\hline & & & 2.00 & & $52.2 \pm 1.1$ & $1.9 \pm 0.1$ & \\
\hline & & & 4.00 & & $53.1 \pm 1.5$ & $1.9 \pm 0.1$ & \\
\hline \multirow{5}{*}{ Talc } & 0 & \multirow{5}{*}{ PLA-g-MA } & 0.00 & \multirow{5}{*}{\begin{tabular}{|c|} 
Twin screw, \\
$25 / 95 / 145 / 165 / 175 / 180 /$ \\
$180 / 180 / 175 / 170100^{\circ} \mathrm{C}$
\end{tabular}} & $58.7 \pm 2.2$ & $4.3 \pm 1.0$ & \multirow{5}{*}[164]{} \\
\hline & \multirow{4}{*}{40} & & 0.00 & & $59.6 \pm 2.2$ & $1.1 \pm 0.2$ & \\
\hline & & & 3.00 & & $66.0 \pm 3.1$ & $0.9 \pm 0.1$ & \\
\hline & & & 5.00 & & $72.4 \pm 1.8$ & $1.5 \pm 0.1$ & \\
\hline & & & 10.00 & & $24.1 \pm 2.3$ & $0.3 \pm 0.1$ & \\
\hline \multirow{6}{*}{ Wheat starch } & \multirow{2}{*}{0} & \multirow{4}{*}{$\begin{array}{l}\text { 2,5-bis(tert-butylperoxy)-2,5 } \\
\text { dimethylhexane }\end{array}$} & 0.00 & & $61.6 \pm 3.8$ & $5.2 \pm 0.5$ & \\
\hline & & & 0.01 & & $54.3 \pm 3.5$ & $4.9 \pm 0.3$ & \\
\hline & & & 0.00 & Twin screw, & $30.0 \pm 2.6$ & $2.7 \pm 0.1$ & {$[16]$} \\
\hline & & & 0.01 & $125 / 185 / 185^{\circ} \mathrm{C}$ & $35.4 \pm 3.6$ & $4.0 \pm 0.2$ & [165] \\
\hline & 45 & 2,5-bis(tert-butylperoxy)-2,5 & $0.05+0.5$ & & $50.0 \pm 1.9$ & $3.7 \pm 0.4$ & \\
\hline & & dimethylhexane + maleic anhydride & $0.1+1$ & & $52.4 \pm 1.9$ & $4.1 \pm 0.1$ & \\
\hline
\end{tabular}

Chikh et al. [171] prepared poly(3-hydroxybutyrateco-3-hydroxyvalerate)/poly(butylene succinate) (PHBV/PBS) blends and PHBV/PBS/sepiolite nanocomposites compatibilized with maleic anhydride grafted poly(3-hydroxybutyrate-co-3-hydroxyvalerate) (PHBV-g-MA). Morphological studies showed that dispersion of PBS markedly became finer with incorporation of sepiolite and PHBV-g-MA, resulting form enhanced interactions between used components. This suggested synergistic effect of chemical compatibilizer (PHBV-g-MA) and nano-filler (sepiolite) which had beneficial impact on the final properties of studied materials.

Zhang and Zhang [172] successfully improved thermal stability and mechanical properties of PBS/PLA blends using reactive processing in presence of DCP and PBS-g-cellulose nanocrystals as compatibilizers.
Observed reinforcement effect is related to the limited molecular segmental mobility of PBS/PLA matrix, resulting from chemical cross-linking using DCP and physical interactions with PBS- $g$-cellulose nanocrystals.

Zhang et al. [173] prepared PHBV/PBAT blends reinforced with miscanthus biofiber, which were compatibilized using ENR and DCP. The results indicated that ENR in the presence of DCP acts like effective coupling agent and simultaneously impact modifier of studied materials. This confirms synergistic effect of DCP and ENR, which significantly improving the compatibility of PHBV/PBAT/miscanthus biofiber biocomposites.

Morelli et al. [174] have fabricated biocomposites based on PBAT and phenylbutyl isocyanate modified with cellulose nanocrystals (pbCNC), which properties 


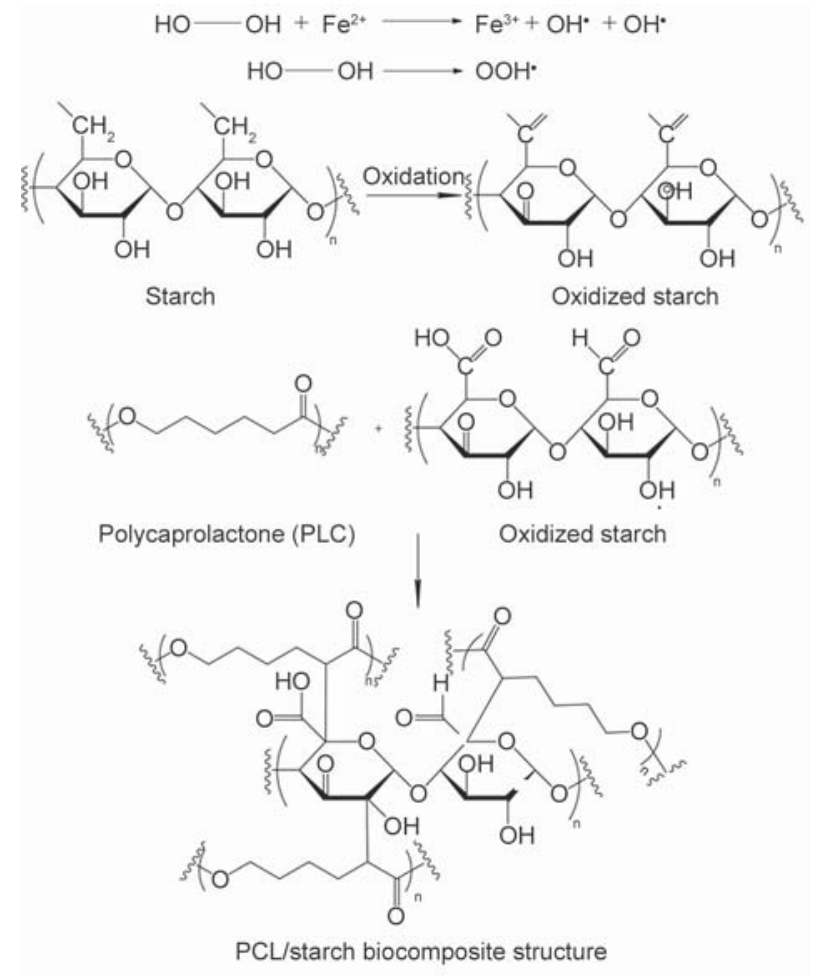

Figure 21. The scheme of starch oxidation and cross-linking pathway of oxidized starch and PCL. Scheme is based on [168].

were compared PBAT with unmodified cellulose nanocrystals (CNC) composites obtained in the same conditions. It was found that $\mathrm{PBAT} / \mathrm{CNC}$ and $\mathrm{PBAT} / \mathrm{pbCNC}$ were characterized by elastic modulus $55 \%$ higher and water vapor permeability $63 \%$ lower than pure PBAT, without change of its biodegradation. Furthermore, it was observed that appearance of PBAT/pbCNC biocomposites samples were similar to pure PBAT. However, during further research in this area, the biocomposites could be prepared in one step reactive extrusion.

The presented above state of knowledge confirms that for bio-based polymer blends and composites the mostly used compatibilizers are free radial initiators, which is related to their affordable price and industrial availability. In this field, a special attention is focused on organic peroxides, among which the most popular are dicumyl peroxide (DCP) and 2,5dimethyl-2,5-di(tert-butylperoxy)-hexane organic peroxide (L101). Free radial initiators during reactive extrusion allow controlled degradation and dynamic curing of biodegradable polymer blends. Furthermore, high temperature necessary to decompose of organic peroxide enhance also transesterification reactions of aliphatic polyesters. Above mentioned reactions usually resulted in formulation of new oligomers or copolymers which act like interface compatibilizers between two (or more) separate phases and improve the physico-mechanical properties of obtained blends. On the other hand, it should be pointed that selected by-products of organic peroxides decomposition (e.g. acetophenone) or volatile organic compounds formed during peroxides induced degradation might affect the performance properties of biodegradable polymeric materials and consequently their potential application [175]. Therefore, it is very important to evaluate the correlations between VOCs characteristics and structure-properties of the novel bio-based polymeric materials, what should be the aim of further studies in this field.

Moreover, organic peroxides are used during grafting of polymer blends by functional monomers (mostly: maleic anhydride and glycidyl methacrylate), while obtained grafted polymers are also commonly used as compatibilizers.

It seems that due to economic reasons, future trends in compatibilization strategy of biodegradable polymer blends and composites will be focused on dynamic curing, grafting and application of commercial chain extenders or functional monomers. Additionally, very promising route for tailoring the final properties of bio-based polymer blends and composites are relatively new methods combined chemical and physical compatibilization of bio-based materials, such as application of grafting/curing and nanofillers $[176,177]$ or reactive nanoparticles [178$180]$, which in our opinion should successfully develop in near future.

\section{Conclusions}

Over the last ten years, since first comprehensive review about reactive extrusion of biodegradable polymers was published, we could observe dynamic development of research works about reactive extrusion processing of bio-based polymer blends and composites. This confirms that reactive extrusion is currently one of the most promising processing methods for short time and efficient synthesis of novel polymeric materials, their blends and composites with desired properties. However, appropriate designing of reactive extrusion processes requires determining the correlation between variable processing conditions and the course of chemical reactions inside the extruder barrel. This knowledge usually based on high cost and time consuming comprehensive experimental works, which can be partially reduced by using of test 


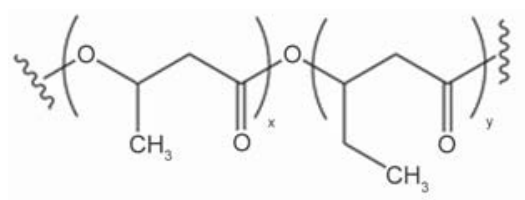

PHBV<smiles>C[13CH]1CC[13CH]1</smiles>

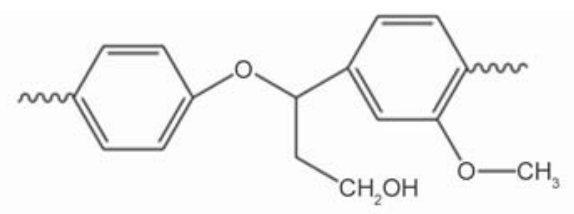

Lignin (partial structure)

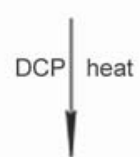<smiles>CCC(CC(C)C)OC(C)CC(=O)CC(C)OC</smiles><smiles>COc1ccc(C(CCO)Oc2ccc(C)cc2)cc1OC</smiles>

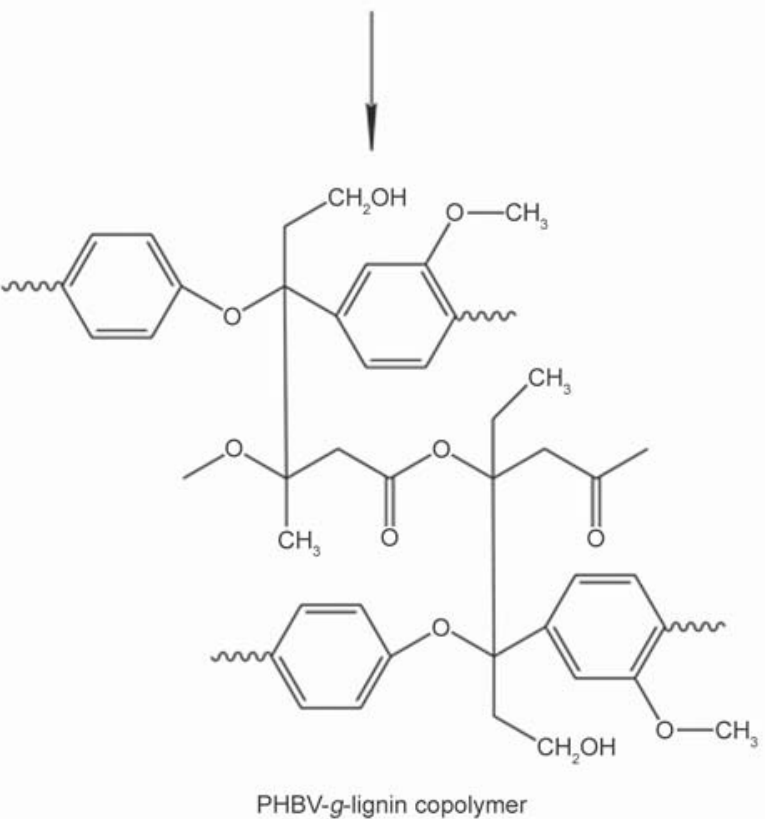

Figure 22. Possible mechanism of reactions between PHBV, lignin and DCP. Scheme is based on [170].

design methods and computer simulations, such as response surface methodology or artificial neural networks. Furthermore, 'on-line' and 'in-line' measurement systems for quality control of extruded polymeric materials should be considered as promising routes to support and accelerate optimization of extrusion process.

Reactive extrusion allows easy tailoring the properties of fabricated materials controlled by the polymeric material compositions and their processing conditions. Moreover, shear forces inside the extruder should be sufficient for reactive groups to encounter one another. This can be achieved by using a co-rotating twin screw extruders or a triple screw extruders with segmented/modular screw and barrel construction, which might be successfully changed or modified. Additionally, to enhance processing of biobased polymer blends and composites, the reactive extrusion process could be assisted by ultrasounds, supercritical fluids or enzymes.

The state of knowledge presented above indicated that the production and processing of chemically modified biodegradable polymers, functionalized natural fillers/fibers or effective compatibilization of bio-based polymer blends and composites using reactive extrusion will continue to grow in the future. However, it seems that current and also future trends in the research field of biodegradable polymeric materials reactive processing will be focus on two main, relatively new directions. First direction is related to 3D printing technology and production of new filaments based on different kinds of bio-based polymer blends and composites. Reactive extrusion allows preparing of the novel biodegradable materials, while their processing and performance properties can be tailored by addition of reactive modifiers (e.g. 
dicumyl peroxide, maleic anhydride, epoxidized natural rubber, etc.) or application of variable extrusion conditions (e.g. temperature, shear forces, etc.). The obtained biodegradable materials could be successfully used as filaments during 3D printing in versatile applications, e.g. industrial design, automobiles, architecture, mechanical engineering, biomedical engineering, etc. Second promising direction for further development of reactive extrusion, in the field of bio-based polymers and composites, is modification or functionalization of widespread used cellulose-rich fillers, such as wood dust, natural fibers or agriculture wastes. The current research trends confirmed that reactive extrusion can be considered as a fast, solvent-free, low-cost and pro-ecologic alternative for 'conventional' modification methods of natural filler/fibers.

\section{Acknowledgements}

Financial support from Spanish Ministry of Economy and Competitiveness and European Union (MINECO/FEDER and UE) in the frame of MAT2015-66149-P project is gratefully acknowledged.

$\begin{array}{ll}\text { Abbreviations } \\ \text { BGE } & \text { butyl glycidyl ether } \\ \text { CNC } & \text { cellulose nanocrystal } \\ \text { DCP } & \text { dicumyl peroxide } \\ \text { EF-PLA } & \text { epoxy functionalized poly(lactic acid) } \\ \text { ENR } & \text { epoxidized natural rubber } \\ \text { ECA } & \text { epoxidized citric acid } \\ \text { ESO } & \text { epoxidized soybean oil } \\ \text { GMA } & \text { glycidyl methacrylate } \\ \text { HDI } & \text { hexamethylene diisocyanate } \\ \text { LTI } & \text { lysine triisocyanate } \\ \text { LDI } & \text { lysine diisocyanate } \\ \text { MA } & \text { maleic anhydride } \\ \text { MCC } & \text { microcrystalline cellulose } \\ \text { MDI } & \text { methylene diphenyl diisocyanate } \\ \text { Mg } & \text { megagram } \\ \text { NFCs } & \text { natural fiber composites } \\ \text { NR } & \text { natural rubber } \\ \text { NR-g-PMMA } & \text { poly(methyl methacrylate) grafted natural } \\ & \text { rubber grafted } \\ \text { NR-g-GMA } & \text { glycidyl methacrylate grafted natural rubber } \\ \text { NR-g-PBA } & \text { poly(butyl acrylate) grafted natural rubber } \\ \text { PA } & \text { phthalic anhydride } \\ \text { pbCNC } & \text { phenylbutyl isocyanate modified with cellu- } \\ & \text { lose nanocrystals } \\ \text { PBAT } & \text { poly(butylene-adipate-co-terephtalate) } \\ \text { PBS } & \text { poly(butylene succinate) } \\ \text { PBSA } & \text { poly(butylene succinate-co-adipate) } \\ \text { PCL } & \text { poly(e-caprolactone) } \\ & \end{array}$

PCL-g-GMA glycidyl methacrylate grafted poly(caprolactone)

PCL-g-DEM diethyl maleate grafted poly(caprolactone)

PHB poly(3-hydroxybutyrate)

PHBV poly(3-hydroxybutyrate-co-3-hydroxyvalerate)

PHBV-g-MA maleic anhydride grafted poly(3-hydroxybutyrate-co-3-hydroxyvalerate)

phr parts per hundred of resin

PLA poly(lactic acid)

CNC-g-PLA poly(lactic acid) grafted cellulose nanocrystal PLA-g-MA maleic anhydride grafted poly(lactic acid)

PLA-g-GMA glycidyl methacrylate grafted poly(lactic acid)

starch-g-MA maleic anhydride grafted starch

TBT tetrabutyl titanate

TDI toluene diisocyanate

TPS thermoplastic starch

WPCs wood polymer composites

\section{References}

[1] PlasticEurope report: Plastics - The facts 2015: An analysis of European plastics production, demand and waste data (2015).

[2] Singh N., Hui D., Singh R., Ahuja I. P. S., Feo L., Fraternali F.: Recycling of plastic solid waste: A state of art review and future applications. Composites Part B: Engineering, 115, 409-422 (2016).

https://doi.org/10.1016/j.compositesb.2016.09.013

[3] Datta J., Kopczyńska P.: From polymer waste to potential main industrial products: Actual state of recycling and recovering. Critical Reviews in Environmental Science and Technology, 46, 905-946 (2016). https://doi.org/10.1080/10643389.2016.1180227

[4] Comăniță E-D., Hlihor R. M., Ghinea C., Gavrilescu M.: Occurrence of plastic waste in the environment: Ecological and health risks. Environmental Engineering and Management Journal, 15, 675-685 (2016).

[5] Marin E., Briceño M. I., Caballero-George C.: Critical evaluation of biodegradable polymers used in nanodrugs. International Journal of Nanomedicine, 8, 30713091 (2013). https://doi.org/10.2147/IJN.S47186

[6] Chandra R., Rustgi R.: Biodegradable polymers. Progress in Polymer Science, 23, 1273-1335 (1998). https://doi.org/10.1016/S0079-6700(97)00039-7

[7] Vroman I., Tighzert L.: Biodegradable polymers. Materials, 2, 307-344 (2009). https://doi.org/10.3390/ma2020307

[8] European Bioplastics, Institute for Bioplastics and Biocomposites, nova-Institute (2015).

[9] Ultracki L. A.: Polymer blends handbook. Kluwer, Dordrecht (2002).

[10] Isayev A. I.: Encyclopedia of polymer blends, Volume 2: Processing. Wiley, Weinheim (2011). 
[11] Ostafinska A., Fortelny I., Nevoralova M., Hodan J., Kredatusova J., Slouf M.: Synergistic effects in mechanical properties of PLA/PCL blends with optimized composition, processing, and morphology. RSC Advances, 5, 98971-98982 (2015). https://doi.org/10.1039/C5RA21178F

[12] Hejna A., Formela K., Saeb M. R.: Processing, mechanical and thermal behavior assessments of polycaprolactone/agricultural wastes biocomposites. Industrial Crops and Products, 76, 725-733 (2015). https://doi.org/10.1016/j.indcrop.2015.07.049

[13] Malinowski R., Bajer K., Moraczewski K., Rytlewski P., Raszkowska-Kaczor A., Janczak K., Żuk T.: Influence of specific processing conditions and aliphaticaromatic copolyester on polylactide properties. Chemical Engineering Communications, 203, 1540-1546 (2016).

https://doi.org/10.1080/00986445.2015.1134517

[14] Sakai T.: Screw extrusion technology - Past, present and future. Polimery, 58, 847-857 (2013). https://doi.org/10.14314/polimery.2013.847

[15] Hamad K., Kaseem M., Ko Y. G., Deri F.: Biodegradable polymer blends and composites: An overview. Polymer Science Series A, 56, 812-829 (2014). https://doi.org/10.1134/S0965545X14060054

[16] Marinho J. F., Braga N. F., Krohn A., Myata F. S., Silveira L. H., Neto A. C., Fechine G. J. M.: Melt processing of polymer biocomposites. Polímeros, 25, 133 136 (2015).

https://doi.org/10.1590/0104-1428.1847

[17] Imre B., Pukánszky B.: Compatibilization in bio-based and biodegradable polymer blends. European Polymer Journal, 49, 1215-1233 (2013). https://doi.org/10.1016/j.eurpolymj.2013.01.019

[18] Ray D.: Biocomposites for high-performance applications. Woodhead, Kidlington (2017).

[19] Raquez J-M., Degée P., Nabar Y., Narayan R., Dubois P.: Biodegradable materials by reactive extrusion: From catalyzed polymerization to functionalization and blend compatibilization. Comptes Rendus Chimie, 9, 1370-1379 (2006).

https://doi.org/10.1016/j.crci.2006.09.004

[20] Raquez J-M., Narayan R., Dubois P.: Recent advances in reactive extrusion processing of biodegradable polymer-based compositions. Macromolecular Materials and Engineering, 293, 447-470 (2008). https://doi.org/10.1002/mame.200700395

[21] Raquez J-M., Ramy-Ratiarison R., Murariu M., Dubois P.: Reactive extrusion of PLA-based materials: From synthesis to reactive melt-blending. in 'Poly(lactic acid) science and technology: Processing, properties, additives and applications' (eds.: Jiménez A., Peltzer M., Ruseckaite R.) Royal Society of Chemistry, Cambridge, 99-123 (2014).

https://doi.org/10.1039/9781782624806-00099
[22] Bonnet F., Stoffelbach F., Fontaine G., Bourbigot S.: Continuous cyclo-polymerisation of L-lactide by reactive extrusion using atoxic metal-based catalysts: Easy access to well-defined polylactide macrocycles. RSC Advances, 5, 31303-31310 (2015).

https://doi.org/10.1039/C4RA16634E

[23] Spinella S., Ganesh M., Lo Re G., Zhang S., Raquez J-M., Dubois P., Gross R. A.: Enzymatic reactive extrusion: Moving towards continuous enzyme-catalysed polyester polymerisation and processing. Green Chemistry, 17, 4146-4150 (2015). https://doi.org/10.1039/C5GC00992H

[24] Gibril M. E., Huan L., haiFeng L., Xin Da L., Yue Z., Han K., Muhuo Y.: Reactive extrusion process for the preparation of a high concentration solution of cellulose in ionic liquid for in situ chemical modification. RSC Advances, 3, 1021-1024 (2013). https://doi.org/10.1039/C2RA22296E

[25] Korol J., Lenża J., Formela K.: Manufacture and research of TPS/PE biocomposites properties. Composites Part B: Engineering, 68, 310-316 (2015). https://doi.org/10.1016/j.compositesb.2014.08.045

[26] de Graaf R. A., Broekroelofs A., Janssen L. P. B. M.: The acetylation of starch by reactive extrusion. Starch, 50, 198-205 (1998).

https://doi.org/10.1002/(SICI)1521379X(199805)50:5<198::AID-STAR198>3.0.CO;2-O

[27] Sheth M., Kumar R. A., Davé V., Gross R. A., McCarthy S. P.: Biodegradable polymer blends of poly (lactic acid) and poly(ethylene glycol). Journal of Applied Polymer Science, 66, 1495-1505 (1997).

https://doi.org/10.1002/(SICI)10974628(19971121)66:8<1495::AID-APP10>3.0.CO;2-3

[28] Nan J., Baorui Y., Yingsheng X.: Three screw rod extruder for polymer. Chinese patent CN 2471522 Y, China (2001).

[29] Zhu X. Z., Wang G., He Y. D., Cheng Z. F.: Study of dynamic flow and mixing performances of tri-screw extruders with finite element method. Advances in Mechanical Engineering, 5, 236389/1-236389/12 (2013). https://doi.org/10.1155/2013/236389

[30] Wang G., Zhu X. Z., He Y. D., Chen L.: Effects of screw clearance and blend ratio on the flow and mixing characteristics of tri-screw extruders in cross section with CFD. Engineering Applications of Computational Fluid Mechanics, 7, 74-89 (2013). https://doi.org/10.1080/19942060.2013.11015455

[31] Sun J., Yang K., Yu D., He Y.: Exploring the mixing performance of triple-screw extruders. Plastics Research Online, 2014, 005418/1-005418/3 (2014). https://doi.org/10.2417/spepro.005418

[32] Zhu X. Z., Xie Y. J., Yuan H. Q.: Numerical simulation of extrusion characteristics for co-rotating tri-screw extruder. Polymer-Plastics Technology and Engineering, 46, 401-407 (2007). https://doi.org/10.1080/03602550701242919 
[33] Jiang N., Zhu C.: Study on extrusion characteristics of the tri-screw extruder. Polymer-Plastics Technology and Engineering, 47, 590-594 (2008). https://doi.org/10.1080/03602550802059105

[34] Zhu X. Z., Yuan H. Q., Wang W. Q.: Numerical simulation of flow characteristics in new co-rotating triangle arrayed triple screw extruders. Journal of Materials Processing Technology, 209, 3289-3299 (2009). https://doi.org/10.1016/j.jmatprotec.2008.07.045

[35] Zhu X. Z., He Y. D., Wang G.: Effect of dynamic center region on the flow and mixing efficiency in a new tri-screw extruder using 3D finite element modeling. International Journal of Rotating Machinery, 2013, 258197/1-258197/12 (2013).

https://doi.org/10.1155/2013/258197

[36] Yang K., Xin C., Yu D., Yan B., Pang J., He Y.: Numerical simulation and experimental study of pressure and residence time distribution of triple-screw extruder. Polymer Engineering and Science, 55, 156-162 (2015). https://doi.org/10.1002/pen.23883

[37] Peng X-F., Li K-C., Mi H-Y., Jing X., Chen B-Y.: Excellent properties and extrusion foaming behavior of PPC/PS/PTFE composites with an in situ fibrillated PTFE nanofibrillar network. RSC Advances, 6, 31763185 (2016). https://doi.org/10.1039/C5RA19965D

[38] Zhang W-H., Fu D-J., Chen B-Y., Wang T., Peng X-F.: Preparation and microcellular foaming investigation of poly(lactic acid)/talc composites. SPE ANTEC Conference Proceedings, 1, 606-610 (2013).

[39] Yu P., Chen B-Y., Kuang T-R., Peng X-F.: Preparation and characterization of poly(lactic acid)/poly(vinyl alcohol) blend. SPE ANTEC Conference Proceedings, 2, 1023-1026 (2013).

[40] Zhang W., Chen B., Zhao H., Yu P., Fu D., Wen J., Peng $\mathrm{X}$.: Processing and characterization of supercritical $\mathrm{CO}_{2}$ batch foamed poly(lactic acid)/poly(ethylene glycol) scaffold for tissue engineering application. Journal of Applied Polymer Science, 130, 3066-3073 (2013). https://doi.org/10.1002/app.39523

[41] Chen B-Y., Wang Y-S., Mi H-Y., Yu P., Kuang T-R., Peng X-F., Wen J-S.: Effect of poly(ethylene glycol) on the properties and foaming behavior of macroporous poly(lactic acid)/sodium chloride scaffold. Journal of Applied Polymer Science, 131, 41181/1-41181/10 (2014).

https://doi.org/10.1002/app.41181

[42] Chen B-Y., Jing X., Mi H-Y., Zhao H., Zhang W-H., Peng X-F., Turng L-S.: Fabrication of polylactic acid/ polyethylene glycol (PLA/PEG) porous scaffold by supercritical $\mathrm{CO}_{2}$ foaming and particle leaching. Polymer Engineering and Science, 55, 1339-1348 (2015). https://doi.org/10.1002/pen.24073
[43] Espert A., de las Heras L. A., Karlsson S.: Emission of possible odourous low molecular weight compounds in recycled biofibre/polypropylene composites monitored by head-space SPME-GC-MS. Polymer Degradation and Stability, 90, 555-562 (2005).

https://doi.org/10.1016/j.polymdegradstab.2005.03.009

[44] Gągol M., Boczkaj G., Haponiuk J., Formela K.: Investigation of volatile low molecular weight compounds formed during continuous reclaiming of ground tire rubber. Polymer Degradation and Stability, 119, 113-120 (2015). https://doi.org/10.1016/j.polymdegradstab.2015.05.007

[45] Formela K., Wołosiak M., Klein M., Wang S.: Characterization of volatile compounds, structural, thermal and physico-mechanical properties of cross-linked polyethylene foams degraded thermo-mechanically at variable times. Polymer Degradation and Stability, 134, 383-393 (2016).

https://doi.org/10.1016/j.polymdegradstab.2016.11.011

[46] Väisänen T., Haapala A., Lappalainen R., Tomppo L.: Utilization of agricultural and forest industry waste and residues in natural fiber-polymer composites: A review. Waste Management, 54, 62-73 (2016). https://doi.org/10.1016/j.wasman.2016.04.037

[47] Datta J., Głowińska E.: Influence of cellulose on mechanical and thermomechanical properties of elastomers obtained from mixtures containing natural rubber (in Polish). Polimery, 56, 823-827 (2011).

[48] Czaplicka-Kolarz K., Burchart-Korol D., Korol J.: Environmental assessment of biocomposites based on LCA (in Polish). Polimery, 58, 605-609 (2013). https://doi.org/10.14314/polimery.2013.476

[49] Sałasińska K., Ryszkowska J.: The effect of filler chemical constitution and morphological properties on the mechanical properties of natural fiber composites. Composite Interfaces, 22, 39-50 (2015). https://doi.org/10.1080/15685543.2015.984521

[50] Mohammed L., Ansari M. N. M., Pua G., Jawaid M., Islam M. S.: A review on natural fiber reinforced polymer composite and its applications. International Journal of Polymer Science, 2015, 243947/1-243947/15 (2015). https://doi.org/10.1155/2015/243947

[51] Dunne R., Desai D., Sadiku R., Jayaramudu J.: A review of natural fibres, their sustainability and automotive applications. Journal of Reinforced Plastics and Composites, 35, 1041-1050 (2016). https://doi.org/10.1177/0731684416633898

[52] Korol J., Burchart-Korol D., Pichlak M.: Expansion of environmental impact assessment for eco-efficiency evaluation of biocomposites for industrial application. Journal of Cleaner Production, 113, 144-152 (2016). https://doi.org/10.1016/j.jclepro.2015.11.101

[53] Sobczak L., Brüggemann O., Putz R. F.: Polyolefin composites with natural fibers and wood-modification of the fiber/filler-matrix interaction. Journal of Applied Polymer Science, 127, 1-17 (2013). https://doi.org/10.1002/app.36935 
[54] Pickering K. L., Aruan Efendy M. G., Le T. M.: A review of recent developments in natural fibre composites and their mechanical performance. Composites Part A: Applied Science and Manufacturing, 83, 98$112(2016)$

https://doi.org/10.1016/j.compositesa.2015.08.038

[55] Cailloux J., Santana O. O., Franco-Urquiza E., Bou J. J., Carrasco F., Gamez-Pérez J., Maspoch M. L.: Sheets of branched poly(lactic acid) obtained by one step reactive extrusion calendering process: Melt rheology analysis. Express Polymer Letters, 7, 304-318 (2013). https://doi.org/10.3144/expresspolymlett.2013.27

[56] Schneider J., Bourque K., Narayan R.: Moisture curable toughened poly(lactide) utilizing vinyltrimethoxysilane based crosslinks. Express Polymer Letters, 10, 799-809 (2016). https://doi.org/10.3144/expresspolymlett.2016.75

[57] Renner K., Kenyó C., Móczó J., Pukánszky B.: Micromechanical deformation processes in $\mathrm{PP} /$ wood composites: Particle characteristics, adhesion, mechanisms. Composites Part A: Applied Science and Manufacturing, 41, 1653-1661 (2010).

https://doi.org/10.1016/j.compositesa.2010.08.001

[58] Colom X., Carrasco F., Pagés P., Cañavate J.: Effects of different treatments on the interface of HDPE/lignocellulosic fiber composites. Composites Science and Technology, 63, 161-169 (2003). https://doi.org/10.1016/S0266-3538(02)00248-8

[59] Xie Y., Hill C. A. S., Xiao Z., Militz H., Mai C.: Silane coupling agents used for natural fiber/polymer composites: A review. Composites Part A: Applied Science and Manufacturing, 41, 806-819 (2010). https://doi.org/10.1016/j.compositesa.2010.03.005

[60] Colom X., Carrillo. F.: Crystallinity changes in lyocell and viscose-type fibres by caustic treatment. European Polymer Journal, 38, 2225-2230 (2002). https://doi.org/10.1016/S0014-3057(02)00132-5

[61] Corradini E., de Morais L. C., de F. Rosa M., Mazzetto S. E., Mattoso L. H. C., Agnelli J. A. M.: A preliminary study for the use of natural fibers as reinforcement in starch-gluten-glycerol matrix. Macromolecular Symposia, 245-246, 558-564 (2006).

https://doi.org/10.1002/masy.200651380

[62] Rowell R. M.: Acetylation of natural fibers to improve performance. Molecular Crystals and Liquid Crystals, 418, 153-164 (2004).

https://doi.org/10.1080/15421400490479244

[63] Błędzki A. K., Mamun A. A., Lucka-Gabor M., Gutowski V. S.: The effects of acetylation on properties of flax fibre and its polypropylene composites. Express Polymer Letters, 2, 413-422 (2008). https://doi.org/10.3144/expresspolymlett.2008.50

[64] Cantero G., Arbelaiz A., Llano-Ponte R., Mondragon I.: Effects of fibre treatment on wettability and mechanical behaviour of flax/polypropylene composites. Composites Science and Technology, 63, 1247-1254 (2003).

https://doi.org/10.1016/S0266-3538(03)00094-0
[65] Baiardo M., Frisoni G., Scandola M., Licciardello A.: Surface chemical modification of natural cellulose fibers. Journal of Applied Polymer Science, 83, 38-45 (2002). https://doi.org/10.1002/app.2229

[66] Fox S. C., Li B., Xu D., Edgar K. J.: Regioselective esterification and etherification of cellulose: A review. Biomacromolecules, 12, 1956-1972 (2011).

https://doi.org/10.1021/bm200260d

[67] Suwanruji P., Tuechart T., Smitthipong W., Chollakup R.: Modification of pineapple leaf fiber surfaces with silane and isocyanate for reinforcing thermoplastic. Journal of Thermoplastic Composite Materials, 2016, 1-17 (2016).

https://doi.org/10.1177/0892705716632860

[68] Datta J., Kopczyńska P.: Effect of kenaf fibre modification on morphology and mechanical properties of thermoplastic polyurethane materials. Industrial Crops and Products, 74, 566-576 (2015).

https://doi.org/10.1016/j.indcrop.2015.05.080

[69] Carrillo F., Defays B., Colom X.: Surface modification of lyocell fibres by graft copolymerization of thermosensitive poly- $N$-isopropylacrylamide. European Polymer Journal, 44, 4020-4028 (2008).

https://doi.org/10.1016/j.eurpolymj.2008.09.033

[70] Hill C. A. S., Cetin N. S.: Surface activation of wood for graft polymerisation. International Journal of Adhesion and Adhesives, 20, 71-76 (2000). https://doi.org/10.1016/S0143-7496(99)00017-2

[71] Li X., Tabil L. G., Panigrahi S.: Chemical treatments of natural fiber for use in natural fiber-reinforced composites: A review. Journal of Polymers and the Environment, 15, 25-33 (2007). https://doi.org/10.1007/s10924-006-0042-3

[72] Raj R. G., Kokta B. V.: Reinforcing high density polyethylene with cellulosic fibers. I: The effect of additives on fiber dispersion and mechanical properties. Polymer Engineering and Science, 31, 1358-1362 (1991). https://doi.org/10.1002/pen.760311811

[73] Jamil M. S., Ahmad I., Abdullah I.: Effects of rice husk filler on the mechanical and thermal properties of liquid natural rubber compatibilized high-density polyethylene/natural rubber blends. Journal of Polymer Research, 13, 315-321 (2006). https://doi.org/10.1007/s10965-005-9040-8

[74] Dányádi L., Móczó J., Pukánszky B.: Effect of various surface modifications of wood flour on the properties of PP/wood composites. Composites Part A: Applied Science and Manufacturing, 41, 99-206 (2010). https://doi.org/10.1016/j.compositesa.2009.10.008

[75] Carlborn K., Matuana L. M.: Functionalization of wood particles through a reactive extrusion process. Journal of Applied Polymer Science, 101, 3131-3142 (2006). https://doi.org/10.1002/app.22577 
[76] Carlborn K., Matuana L. M.: Composite materials manufactured from wood particles modified through a reactive extrusion process. Polymer Composites, 26, 534-541 (2005).

https://doi.org/10.1002/pc.20122

[77] Wei L., McDonald A. G., Stark N. M.: Grafting of bacterial polyhydroxybutyrate (PHB) onto cellulose via in situ reactive extrusion with dicumyl peroxide. Biomacromolecules, 16, 1040-1049 (2015).

https://doi.org/10.1021/acs.biomac.5b00049

[78] Bhandari P. N., Jones D. D., Hanna M. A.: Carboxymethylation of cellulose using reactive extrusion. Carbohydrate Polymers, 87, 2246-2254 (2012).

https://doi.org/10.1016/j.carbpol.2011.10.056

[79] Zhang Y., Li H., Li X., Gibril M. E., Yu M.: Chemical modification of cellulose by in situ reactive extrusion in ionic liquid. Carbohydrate Polymers, 99, 126-131 (2014).

https://doi.org/10.1016/j.carbpol.2013.07.084

[80] Vandenbossche V., Brault J., Vilarem G., HernándezMeléndez O., Vivaldo-Lima E., Hernández-Luna M., Barzana E., Duque A., Manzanares P., Ballesteros M., Mata J., Castellón E., Rigal L.: A new lignocellulosic biomass deconstruction process combining thermomechano chemical action and bio-catalytic enzymatic hydrolysis in a twin-screw extruder. Industrial Crops and Products, 55, 258-266 (2014).

https://doi.org/10.1016/j.indcrop.2014.02.022

[81] Vandenbossche V., Brault J., Vilarem G., Riga L.: Biocatalytic action of twin-screw extruder enzymatic hydrolysis on the deconstruction of annual plant material: Case of sweet corn co-products. Industrial Crops and Products, 67, 239-248 (2015).

https://doi.org/10.1016/j.indcrop.2015.01.041

[82] Vandenbossche V., Brault J., Hernandez-Melendez O., Evon P., Barzana E., Vilarem G., Rigal L.: Suitability assessment of a continuous process combining thermo-mechano-chemical and bio-catalytic action in a single pilot-scale twin-screw extruder for six different biomass sources. Bioresource Technology, 211, 146153 (2016).

https://doi.org/10.1016/j.biortech.2016.03.072

[83] Evon P., Vandenbossche V., Labonne L., Vinet J., Pontalier P-Y., Rigal L.: The thermo-mechano-chemical twin-screw reactor, a new perspective for the biorefinery of sunflower whole plant: Aqueous extraction of oil and other biopolymers, and production of biodegradable fiberboards from cake. Oilseeds and fats, Crops and Lipids, 23, D505/1-D505/13 (2015). https://doi.org/10.1051/ocl/2016034

[84] Zhang S., Keshwani D. R., Xu Y., Hanna M. A.: Alkali combined extrusion pretreatment of corn stover to enhance enzyme saccharification. Industrial Crops and Products, 37, 352-357 (2012).

https://doi.org/10.1016/j.indcrop.2011.12.001
[85] Ahmed M. A., Rehman M. S. U., Terán-Hilares R., Khalid S., Han J-I.: Optimization of twin gear-based pretreatment of rice straw for bioethanol production. Energy Conversion and Management, 141, 120-125 (2017).

https://doi.org/10.1016/j.enconman.2016.06.022

[86] Vaidya A. A., Gaugler M., Smith D. A.: Green route to modification of wood waste, cellulose and hemicellulose using reactive extrusion. Carbohydrate Polymers, 136, 1238-1250 (2016).

https://doi.org/10.1016/j.carbpol.2015.10.033

[87] Cardoso M. A. P., Carvalho G. M., Yamashita F., Mali S., Eiras D., Demiate I. M., Grossmann M. V. E.: Oat hull fibers bleached by reactive extrusion with alkaline hydrogen peroxide in thermoplastic starch/poly(butylene adipate-co-terephthalate) composites. Polymer Composites, in press (2016). https://doi.org/10.1002/pc.24151

[88] Yang Z., Feng X., Bi Y., Zhou Z., Yue J., Xu M.: Bleached extruder chemi-mechanical pulp fiber-PLA composites: Comparison of mechanical, thermal, and rheological properties with those of wood flour-PLA bio-composites. Journal of Applied Polymer Science, 133, 44241/1-44241/9 (2016).

https://doi.org/10.1002/app.44241

[89] Harada M., Iida K., Okamoto K., Hayashi H., Hirano K.: Reactive compatibilization of biodegradable poly (lactic acid)/poly( $\varepsilon$-caprolactone) blends with reactive processing agents. Polymer Engineering and Science, 48, 1359-1368 (2008). https://doi.org/10.1002/pen.21088

[90] Takayama T., Todo M., Tsuji H., Arakawa K.: Effect of LTI content on impact fracture property of PLA/PCL/ LTI polymer blends. Journal of Materials Science, 41, 6501-6504 (2006).

https://doi.org/10.1007/s10853-006-0611-9

[91] Takayama T., Todo M., Tsuji H.: Effect of annealing on the mechanical properties of PLA/PCL and PLA/PCL/ LTI polymer blends. Journal of the Mechanical Behavior of Biomedical Materials, 4, 255-260 (2011). https://doi.org/10.1016/j.jmbbm.2010.10.003

[92] Harada M., Ohya T., Iida K., Hayashi H., Hirano K., Fukuda H.: Increased impact strength of biodegradable poly(lactic acid)/poly(butylene succinate) blend composites by using isocyanate as a reactive processing agent. Journal of Applied Polymer Science, 106, 1813-1820 (2007).

https://doi.org/10.1002/app.26717

[93] Gardella L., Calabrese M., Monticelli O.: PLA maleation: An easy and effective method to modify the properties of PLA/PCL immiscible blends. Colloid and Polymer Science, 292, 2391-2398 (2014). https://doi.org/10.1007/s00396-014-3328-3 
[94] Shin Y. B., Han D. H.: Compatibilization of immiscible poly(lactic acid)/poly( $\varepsilon$-caprolactone) blend through electron-beam irradiation with the addition of a compatibilizing agent. Radiation Physics and Chemistry, 83, 98-104 (2013).

https://doi.org/10.1016/j.radphyschem.2012.10.001

[95] Semba T., Kitagawa K., Ishiaku U. S., Hamada H.: The effect of crosslinking on the mechanical properties of polylactic acid/polycaprolactone blends. Journal of Applied Polymer Science, 101, 1816-1825 (2006). https://doi.org/10.1002/app.23589

[96] Semba T., Kitagawa K., Kotaki M., Hamada H.: In situ fibrous structure oriented polymer blends composed of poly(lactic acid) and polycaprolactone containing peroxide. Journal of Applied Polymer Science, 108, 256-263 (2008).

https://doi.org/10.1002/app.27587

[97] Ma P., Cai X., Zhang Y., Wang S., Dong W., Chen M., Lemstra P. J.: In-situ compatibilization of poly(lactic acid) and poly(butylene adipate-co-terephthalate) blends by using dicumyl peroxide as a free-radical initiator. Polymer Degradation and Stability, 102, 145-151 (2014).

https://doi.org/10.1016/j.polymdegradstab.2014.01.025

[98] Signori F., Boggioni A., Righetti M. C., Rondán C. E., Bronco S., Ciardelli F.: Evidences of transesterification, chain branching and cross-linking in a biopolyester commercial blend upon reaction with dicumyl peroxide in the melt. Macromolecular Materials and Engineering, 300, 153-160 (2015).

https://doi.org/10.1002/mame.201400187

[99] Dong W., Ma P., Wang S., Chen M., Cai X., Zhang Y.: Effect of partial crosslinking on morphology and properties of the poly( $\beta$-hydroxybutyrate)/poly(D,L-lactic acid) blends. Polymer Degradation and Stability, 98, 1549-1555 (2013).

https://doi.org/10.1016/j.polymdegradstab.2013.06.033

[100] Wei L., McDonald A. G.: Peroxide induced cross-linking by reactive melt processing of two biopolyesters: Poly(3-hydroxybutyrate) and poly(L-lactic acid) to improve their melting processability. Journal of Applied Polymer Science, 132, 41724/1-41724/15 (2015). https://doi.org/10.1002/app.41724

[101] Ma P., Hristova-Bogaerds D. G., Lemstra P. J., Zhang Y., Wang S.: Toughening of PHBV/PBS and PHB/PBS blends via in situ compatibilization using dicumyl peroxide as a free-radical grafting initiator. Macromolecular Materials and Engineering, 297, 402-410 (2012). https://doi.org/10.1002/mame.201100224

[102] Yang X., Clénet J., Xu H., Odelius K., Hakkarainen M.: Two step extrusion process: From thermal recycling of PHB to plasticized PLA by reactive extrusion grafting of PHB degradation products onto PLA chains. Macromolecules, 48, 2509-2518 (2015).

https://doi.org/10.1021/acs.macromol.5b00235
[103] Lin S., Guo W., Chen C., Ma J., Wang B.: Mechanical properties and morphology of biodegradable poly(lactic acid)/poly(butylene adipate-co-terephthalate) blends compatibilized by transesterification. Materials and Design, 36, 604-608 (2012). https://doi.org/10.1016/j.matdes.2011.11.036

[104] Coltelli M-B., Toncelli C., Ciardelli F., Bronco S.: Compatible blends of biorelated polyesters through catalytic transesterification in the melt. Polymer Degradation and Stability, 96, 982-990 (2011). https://doi.org/10.1016/j.polymdegradstab.2011.01.028

[105] Eslami H., Kamal M. R.: Effect of a chain extender on the rheological and mechanical properties of biodegradable poly(lactic acid)/poly[(butylene succinate)co-adipate] blends. Journal of Applied Polymer Science, 129, 2418-2428 (2013). https://doi.org/10.1002/app.38449

[106] Ojijo V., Ray S. S.: Super toughened biodegradable polylactide blends with non-linear copolymer interfacial architecture obtained via facile in-situ reactive compatibilization. Polymer, 80, 1-17 (2015). https://doi.org/10.1016/j.polymer.2015.10.038

[107] Arruda L. C., Magaton M., Bretas R. E. S., Ueki M. M.: Influence of chain extender on mechanical, thermal and morphological properties of blown films of PLA/ PBAT blends. Polymer Testing, 43, 27-37 (2015). https://doi.org/10.1016/j.polymertesting.2015.02.005

[108] Schneider J., Manjure S., Narayan R.: Reactive modification and compatibilization of poly(lactide) and poly(butylene adipate-co-terephthalate) blends with epoxy functionalized-poly(lactide) for blown film applications. Journal of Applied Polymer Science, 133, 43310/1-43310/9 (2016). https://doi.org/10.1002/app.43310

[109] Zeng J-B., Li K-A., Du A-K.: Compatibilization strategies in poly(lactic acid)-based blends. RSC Advances, 5, 32546-32565 (2015). https://doi.org/10.1039/C5RA01655J

[110] Dubois P., Narayan R.: Biodegradable compositions by reactive processing of aliphatic polyester/polysaccharide blends. Macromolecular Symposia, 198, 233-243 (2003). https://doi.org/10.1002/masy.200350820

[111] Huneault M. A., Li H.: Morphology and properties of compatibilized polylactide/thermoplastic starch blends. Polymer, 48, 270-280 (2007). https://doi.org/10.1016/j.polymer.2006.11.023

[112] Wang N., Yu J., Ma X.: Preparation and characterization of thermoplastic starch/PLA blends by one-step reactive extrusion. Polymer International, 56, 1440-1447 (2007).

https://doi.org/10.1002/pi.2302

[113] Hwang S. W., Shim J. K., Selke S., Soto-Valdez H., Rubino M., Auras R.: Effect of maleic-anhydride grafting on the physical and mechanical properties of poly (L-lactic acid)/starch blends. Macromolecular Materials and Engineering, 298, 624-633 (2013). https://doi.org/10.1002/mame.201200111 
[114] Świerz-Motysia B., Jeziórska R., Szadkowska A., Piotrowska M.: Synthesis and properties of biodegradable polylactide and thermoplastic starch blends (in Polish). Polimery, 56, 271-280 (2011).

[115] Kim C-H., Jung K-M., Kim J-S., Park J-K.: Modification of aliphatic polyesters and their reactive blends with starch. Journal of Polymers and the Environment, 12, 179-187 (2004). https://doi.org/10.1023/B:JOOE.0000038550.11407.ab

[116] Sugih A. K., Drijfhout J. P., Picchioni F., Janssen L. P. B. M., Heeres H. J.: Synthesis and properties of reactive interfacial agents for polycaprolactone-starch blends. Journal of Applied Polymer Science, 114, 2315-2326 (2009).

https://doi.org/10.1002/app.30712

[117] Bossard F., Pillin I., Aubry T., Grohens Y.: Rheological characterization of starch derivatives/polycaprolactone blends processed by reactive extrusion. Polymer Engineering and Science, 48, 1862-1870 (2008). https://doi.org/10.1002/pen.21160

[118] Xiong Z., Yang Y., Feng J., Zhang X., Zhang C., Tang Z., Zhu J.: Preparation and characterization of poly (lactic acid)/starch composites toughened with epoxidized soybean oil. Carbohydrate Polymers, 92, 810816 (2013).

https://doi.org/10.1016/j.carbpol.2012.09.007

[119] Li H., Huneault M. A.: Effect of chain extension on the properties of PLA/TPS blends. Journal of Applied Polymer Science, 122, 134-141 (2011). https://doi.org/10.1002/app.33981

[120] Xiong Z., Ma S., Fan L., Tang Z., Zhang R., Na H., Zhu J.: Surface hydrophobic modification of starch with bio-based epoxy resins to fabricate high-performance polylactide composite materials. Composites Science and Technology, 94, 16-22 (2014).

https://doi.org/10.1016/j.compscitech.2014.01.007

[121] Jun C. L.: Reactive blending of biodegradable polymers: PLA and starch. Journal of Polymers and the Environment, 8, 33-37 (2000). https://doi.org/10.1023/A:1010172112118

[122] Karagoz S., Ozkoc G.: Effects of a diisocyanate compatibilizer on the properties of citric acid modified thermoplastic starch/poly(lactic acid) blends. Polymer Engineering and Science, 53, 2183-2193 (2013). https://doi.org/10.1002/pen.23478

[123] Sobral J. M., Caridade S. G., Sousa R. A., Mano J. F., Reis R. L.: Three-dimensional plotted scaffolds with controlled pore size gradients: Effect of scaffold geometry on mechanical performance and cell seeding efficiency. Acta Biomaterialia, 7, 1009-1018 (2011). https://doi.org/10.1016/j.actbio.2010.11.003

[124] Bose S., Vahabzadeh S., Bandyopadhyay A.: Bone tissue engineering using 3D printing. Materials Today, 16, 496-504 (2013).

https://doi.org/10.1016/j.mattod.2013.11.017
[125] Kuo C-C., Liu L-C., Teng W-F., Chang H-Y., Chien F-M., Liao S-J., Kuo W-F., Chen C-M.: Preparation of starch/acrylonitrile-butadiene-styrene copolymers (ABS) biomass alloys and their feasible evaluation for 3D printing applications. Composites Part B: Engineering, 86, 36-39 (2016).

https://doi.org/10.1016/j.compositesb.2015.10.005

[126] Spontak R. J., Patel N. P.: Thermoplastic elastomers: Fundamentals and applications. Current Opinion in Colloid and Interface Science, 5, 333-340 (2000). https://doi.org/10.1016/S1359-0294(00)00070-4

[127] Kear K. E.: Developments in thermoplastic elastomers. Rapra, Shawbury (2003).

[128] Drobny J. G.: Handbook of thermoplastic elastomers. William Andrew Publishing, Norwich (2007).

[129] Ahmed K.: Eco-thermoplastic elastomer blends developed by compatibilizing chlorinated polyethylene into industrial-waste-filled polypropylene/acrylonitrile butadiene rubber system. Arabian Journal for Science and Engineering, 40, 2929-2936 (2015).

https://doi.org/10.1007/s13369-014-1561-1

[130] Formela K., Korol J., Saeb M. R.: Interfacially modified LDPE/GTR composites with non-polar elastomers: From microstructure to macro-behavior. Polymer Testing, 42, 89-98 (2015).

https://doi.org/10.1016/j.polymertesting.2015.01.003

[131] Chatterjee T., Basu D., Das A., Wiessner S., Naskar K., Heinrich G.: Super thermoplastic vulcanizates based on carboxylated acrylonitrile butadiene rubber (XNBR) and polyamide (PA12). European Polymer Journal, 78, 235-252 (2016). https://doi.org/10.1016/j.eurpolymj.2016.03.027

[132] Zhang H., Wang H., Zhong W., Du Q.: A novel type of shape memory polymer blend and the shape memory mechanism. Polymer, 50, 1596-1601 (2009).

https://doi.org/10.1016/j.polymer.2009.01.011

[133] Jantanasakulwong K., Rohindra D., Mori K., Kuboyama K., Ougizawa T.: Thermoplastic elastomer by reactive blending of poly(butylene succinate) with ethylene-propylene-diene terpolymer and ethylene-1butene rubbers. Journal of Elastomers and Plastics, 47, 215-231 (2015).

https://doi.org/10.1177/0095244313507805

[134] Yang J., Nie S., Zhu J.: A comparative study on different rubbery modifiers: Effect on morphologies, mechanical, and thermal properties of PLA blends. Journal of Applied Polymer Science, 133, 43340/1-43340/11 (2016). https://doi.org/10.1002/app.43340

[135] Zhang C., Wang W., Huang Y., Pan Y., Jiang L., Dan Y., Luo Y., Peng Z.: Thermal, mechanical and rheological properties of polylactide toughened by expoxidized natural rubber. Materials and Design, 45, 198-205 (2013).

https://doi.org/10.1016/j.matdes.2012.09.024 
[136] Parulekar Y., Mohanty A. K.: Biodegradable toughened polymers from renewable resources: Blends of polyhydroxybutyrate with epoxidized natural rubber and maleated polybutadiene. Green Chemistry, 8, 206213 (2006).

https://doi.org/10.1039/B508213G

[137] Lee H. K., Ismail J., Kammer H. W., Bakar M. A.: Melt reaction in blends of poly(3-hydroxybutyrate) (PHB) and epoxidized natural rubber (ENR-50). Journal of Applied Polymer Science, 95, 113-129 (2005). https://doi.org/10.1002/app.20808

[138] Nampitch T., Magaraphan R.: Preparation, characterization and properties of ternary blends with epoxidized natural rubber, poly (lactic acid) and poly (butylene adipate-co-terephthalate). Advanced Materials Research, 335-336, 762-768 (2011).

https://doi.org/10.4028/www.scientific.net/AMR.335-336.762

[139] Jaratrotkamjorn R., Khaokong C., Tanrattanakul V.: Toughness enhancement of poly(lactic acid) by melt blending with natural rubber. Journal of Applied Polymer Science, 124, 5027-5036 (2012).

https://doi.org/10.1002/app.35617

[140] Zhang C., Huang Y., Luo C., Jiang L., Dan Y.: Enhanced ductility of polylactide materials: Reactive blending with pre-hot sheared natural rubber. Journal of Polymer Research, 20, 121/1-121/9 (2013). https://doi.org/10.1007/s10965-013-0121-9

[141] Juntuek P., Ruksakulpiwat C., Chumsamrong P., Ruksakulpiwat Y.: Effect of glycidyl methacrylate-grafted natural rubber on physical properties of polylactic acid and natural rubber blends. Journal of Applied Polymer Science, 125, 745-754 (2012).

https://doi.org/10.1002/app.36263

[142] Zhang C., Man C., Pan Y., Wang W., Jiang L., Dan Y.: Toughening of polylactide with natural rubber grafted with poly(butyl acrylate). Polymer International, 60, 1548-1555 (2011).

https://doi.org/10.1002/pi.3118

[143] Mohammad N. N. B., Arsad A., Rahmat A. R., Abdullah Sani N. S., Ali Mohsin M. E.: Influence of compatibilizer on the structure properties of polylactic acid/ natural rubber blends. Polymer Science Series A, 58, 177-185 (2016)

https://doi.org/10.1134/S0965545X16020164

[144] Huang Y., Zhang C., Pan Y., Wang W., Jiang L., Dan Y.: Study on the effect of dicumyl peroxide on structure and properties of poly(lactic acid)/natural rubber blend. Journal of Polymers and the Environment, 21, 375-387 (2013).

https://doi.org/10.1007/s10924-012-0544-0

[145] Chen Y., Yuan D., Xu C.: Dynamically vulcanized biobased polylactide/natural rubber blend material with continuous cross-linked rubber phase. ACS Applied Materials and Interfaces, 6, 3811-3816 (2014).

https://doi.org/10.1021/am5004766
[146] Chen W-C., Lai S-M., Chang M. Y., Liao Z-C.: Preparation and properties of natural rubber (NR)/polycaprolactone (PCL) bio-based shape memory polymer blends. Journal of Macromolecular Science Part B: Physics, 53, 645-661 (2014). https://doi.org/10.1080/00222348.2013.860304

[147] Formela K., Marć M., Namieśnik J., Zabiegała B.: The estimation of total volatile organic compounds emissions generated from peroxide-cured natural rubber/ polycaprolactone blends. Microchemical Journal, 127, 30-35 (2016).

https://doi.org/10.1016/j.microc.2016.02.001

[148] Mishra J. K., Chang Y-W., Kim D-K.: Green thermoplastic elastomer based on polycaprolactone/epoxidized natural rubber blend as a heat shrinkable material. Materials Letters, 61, 3551-3554 (2007). https://doi.org/10.1016/j.matlet.2006.11.119

[149] Mishra J. K., Chang Y-W., Kim W.: The effect of peroxide crosslinking on thermal, mechanical, and rheological properties of polycaprolactone/epoxidized natural rubber blends. Polymer Bulletin, 66, 673-681 (2011). https://doi.org/10.1007/s00289-010-0376-9

[150] Wang Y., Chen K., Xu C., Chen Y.: Supertoughened biobased poly(lactic acid)-epoxidized natural rubber thermoplastic vulcanizates: Fabrication, co-continuous phase structure, interfacial in situ compatibilization, and toughening mechanism. Journal of Physical Chemistry B, 119, 12138-12146 (2015). https://doi.org/10.1021/acs.jpcb.5b06244

[151] Dhar P., Tarafder D., Kumar A., Katiyar V.: Thermally recyclable polylactic acid/cellulose nanocrystal films through reactive extrusion process. Polymer, 87, 268282 (2016). https://doi.org/10.1016/j.polymer.2016.02.004

[152] Rytlewski P., Moraczewski K., Malinowski R., Żenkiewicz M.: Assessment of dicumyl peroxide ability to improve adhesion between polylactide and flax or hemp fibres. Composite Interfaces, 21, 671-683 (2014). https://doi.org/10.1080/15685543.2014.927262

[153] Liu R., Peng Y., Cao J., Chen Y.: Comparison on properties of lignocellulosic flour/polymer composites by using wood, cellulose, and lignin flours as fillers. Composites Science and Technology, 103, 1-7 (2014). https://doi.org/10.1016/j.compscitech.2014.08.005

[154] Peltola H., Pääkkönen E., Jetsu P., Heinemann S.: Wood based PLA and PP composites: Effect of fibre type and matrix polymer on fibre morphology, dispersion and composite properties. Composites Part A: Applied Science and Manufacturing, 61, 13-22 (2014). https://doi.org/10.1016/j.compositesa.2014.02.002

[155] Formela K., Hejna A., Piszczyk Ł., Saeb M. R., Colom $\mathrm{X}$.: Processing and structure-property relationships of natural rubber/wheat bran biocomposites. Cellulose, 23, 3157-3175 (2016). https://doi.org/10.1007/s10570-016-1020-0 
[156] Sajna V. P., Mohanty S., Nayak S. K.: Influence of nanoclay and graft copolymer on the thermal and flammability properties of poly(lactic acid)/banana fiber biocomposites. Journal of Vinyl and Additive Technology, in press (2016).

https://doi.org/10.1002/vnl.21556

[157] Mirzadeh A., Ghasemi H., Mahrous F., Kamal M. R.: Reactive extrusion effects on rheological and mechanical properties of poly(lactic acid)/poly[(butylene succinate)-co-adipate]/epoxy chain extender blends and clay nanocomposites. Journal of Applied Polymer Science, 132, 42664/1-42664/13 (2015).

https://doi.org/10.1002/app.42664

[158] Dai X., Xiong Z., Na H., Zhu J.: How does epoxidized soybean oil improve the toughness of microcrystalline cellulose filled polylactide acid composites? Composites Science and Technology, 90, 9-15 (2014).

https://doi.org/10.1016/j.compscitech.2013.10.009

[159] Khoo R. Z., Chow W. S.: Mechanical and thermal properties of poly(lactic acid)/sugarcane bagasse fiber green composites. Journal of Thermoplastic Composite Materials, 30, 1091-1102 (2015).

https://doi.org/10.1177/0892705715616857

[160] Dai X., Xiong Z., Ma S., Li C., Wang J., Na H., Zhu J.: Fabricating highly reactive bio-based compatibilizers of epoxidized citric acid to improve the flexural properties of polylactide/microcrystalline cellulose blends. Industrial and Engineering Chemistry Research, 54, 3806-3812 (2015).

https://doi.org/10.1021/ie504904c

[161] Dogu B., Kaynak C.: Behavior of polylactide/microcrystalline cellulose biocomposites: Effects of filler content and interfacial compatibilization. Cellulose, 23, 611-622 (2016).

https://doi.org/10.1007/s10570-015-0839-0

[162] Baltazar-y-Jimenez A., Sain M.: Effect of bismaleimide reactive extrusion on the crystallinity and mechanical performance of poly(lactic acid) green composites. Journal of Applied Polymer Science, 124, 3013-3023 (2012).

https://doi.org/10.1002/app.35331

[163] Zhu R., Liu H., Zhang J.: Compatibilizing effects of maleated poly(lactic acid) (PLA) on properties of PLA/ soy protein composites. Industrial and Engineering Chemistry Research, 51, 7786-7792 (2012). https://doi.org/10.1021/ie300118x

[164] Fowlks A. C., Narayan R.: The effect of maleated polylactic acid (PLA) as an interfacial modifier in PLA-talc composites. Journal of Applied Polymer Science, 118, 2810-2820 (2010).

https://doi.org/10.1002/app.32380

[165] Zhang J-F., Sun X.: Mechanical properties of poly(lactic acid)/starch composites compatibilized by maleic anhydride. Biomacromolecules, 5, 1446-1451 (2004). https://doi.org/10.1021/bm0400022
[166] de Campos A., Tonoli G. H. D., Marconcini J. M., Mattoso L. H. C., Klamczynski A., Gregorski K. S., Wood D., Williams T., Chiou B. S., Imam S. H.: TPS/PCL composite reinforced with treated sisal fibers: Property, biodegradation and water-absorption. Journal of Polymers and the Environment, 21, 1-7 (2013).

https://doi.org/10.1007/s10924-012-0512-8

[167] Kalambur S. B., Rizvi S. S. H.: Starch-based nanocomposites by reactive extrusion processing. Polymer International, 53, 1413-1416 (2004).

https://doi.org/10.1002/pi.1478

[168] Kalambur S. B., Rizvi S. S. H.: Biodegradable and functionally superior starch-polyester nanocomposites from reactive extrusion. Journal of Applied Polymer Science, 96, 1072-1082 (2005).

https://doi.org/10.1002/app.21504

[169] Kalambur S. B., Rizvi S. S. H.: Rheological behavior of starch-polycaprolactone (PCL) nanocomposite melts synthesized by reactive extrusion. Polymer Engineering and Science, 46, 650-658 (2006).

https://doi.org/10.1002/pen.20508

[170] Luo S., Cao J., McDonald A. G.: Interfacial improvements in a green biopolymer alloy of poly(3-hydroxybutyrate-co-3-hydroxyvalerate) and lignin via in situ reactive extrusion. ACS Sustainable Chemistry and Engineering, 4, 3465-3476 (2016).

https://doi.org/10.1021/acssuschemeng.6b00495

[171] Chikh A., Benhamida A., Kaci M., Pillin I., Bruzaud S.: Synergistic effect of compatibilizer and sepiolite on the morphology of poly(3-hydroxybutyrate-co-3-hydroxyvalerate)/poly(butylene succinate) blends. Polymer Testing, 53, 19-28 (2016).

https://doi.org/10.1016/j.polymertesting.2016.05.008

[172] Zhang X., Zhang Y.: Reinforcement effect of poly (butylene succinate) (PBS)-grafted cellulose nanocrystal on toughened PBS/polylactic acid blends. Carbohydrate Polymers, 140, 374-382 (2016). https://doi.org/10.1016/j.carbpol.2015.12.073

[173] Zhang K., Misra M., Mohanty A. K.: Toughened sustainable green composites from poly(3-hydroxybutyrate-co-3-hydroxyvalerate) based ternary blends and miscanthus biofiber. ACS Sustainable Chemistry and Engineering, 2, 2345-2354 (2014).

https://doi.org/10.1021/sc500353v

[174] Morelli C. L., Belgacem N., Bretas R. E. S., Bras J.: Melt extruded nanocomposites of polybutylene adipate-co-terephthalate (PBAT) with phenylbutyl isocyanate modified cellulose nanocrystals. Journal of Applied Polymer Science, 133, 43678/1-43678/9 (2016). https://doi.org/10.1002/app.43678

[175] Formela K., Marć M., Wang S., Saeb M. R.: Interrelationship between total volatile organic compounds emissions, structure and properties of natural rubber/ polycaprolactone bio-blends cross-linked with peroxides. Polymer Testing, 60, 405-412 (2017). https://doi.org/10.1016/j.polymertesting.2017.04.024 
[176] Torres-Giner S., Montanes N., Boronat T., Quiles-Carrillo L., Balart R.: Melt grafting of sepiolite nanoclay onto poly(3-hydroxybutyrate-co-4-hydroxybutyrate) by reactive extrusion with multi-functional epoxybased styrene-acrylic oligomer. European Polymer Journal, 84, 693-707 (2016).

https://doi.org/10.1016/j.eurpolymj.2016.09.057

[177] Dhar P., Gaur S. S., Soundararajan N., Gupta A., Bhasney S. M., Milli M., Kumar A., Katiyar V.: Reactive extrusion of polylactic acid/cellulose nanocrystal films for food packaging applications: Influence of filler type on thermomechanical, rheological, and barrier properties. Industrial and Engineering Chemistry Research, 56, 4718-4735 (2017).

https://doi.org/10.1021/acs.iecr.6b04699
[178] Wang H., Dong W., Li Y.: Compatibilization of immiscible polymer blends using in situ formed Janus nanomicelles by reactive blending. ACS Macro Letters, 4, 1398-1403 (2015).

https://doi.org/10.1021/acsmacrolett.5b00763

[179] Wang H., Fu Z., Dong W., Li Y., Li J.: Formation of interfacial Janus nanomicelles by reactive blending and their compatibilization effects on immiscible polymer blends. Journal of Physical Chemistry B, 120, 9240-9252 (2016).

https://doi.org/10.1021/acs.jpcb.6b06761

[180] Wang H., Fu Z., Zhao X., Li Y., Li J.: Reactive nanoparticles compatibilized immiscible polymer blends: Synthesis of reactive $\mathrm{SiO}_{2}$ with long poly(methyl methacrylate) chains and the in situ formation of Janus $\mathrm{SiO}_{2}$ nanoparticles anchored exclusively at the interface. ACS Applied Materials and Interfaces, 9, 1435814370 (2017).

https://doi.org/10.1021/acsami.7b01728 